\title{
Limitations of a morphological criterion of adaptive inference in the fossil record
}

\author{
Matthew J. Ravosa ${ }^{1,2,3 *}$, Rachel A. Menegaz ${ }^{4}$, Jeremiah E. Scott ${ }^{5}$, David J. Daegling ${ }^{6}$ \\ and Kevin R. McAbee ${ }^{1}$ \\ ${ }^{1}$ Department of Biological Sciences, Galvin Life Science Center, University of Notre Dame, Notre Dame, IN 46556, U.S.A. \\ ${ }^{2}$ Department of Aerospace and Mechanical Engineering, University of Notre Dame, Notre Dame, IN 46556, U.S.A. \\ ${ }^{3}$ Department of Anthropology, University of Notre Dame, Notre Dame, IN 46556, U.S.A. \\ ${ }^{4}$ Department of Biomedical and Applied Sciences, Indiana University School of Dentistry, Indianapolis, IN 46202, U.S.A. \\ ${ }^{5}$ Department of Anthropology, Southern Illinois University, Carbondale, IL 62901, U.S.A. \\ ${ }^{6}$ Department of Anthropology, University of Florida, Gainesville, FL 32611, U.S.A.
}

\begin{abstract}
Experimental analyses directly inform how an anatomical feature or complex functions during an organism's lifetime, which serves to increase the efficacy of comparative studies of living and fossil taxa. In the mammalian skull, food material properties and feeding behaviour have a pronounced influence on the development of the masticatory apparatus. Diet-related variation in loading magnitude and frequency induce a cascade of changes at the gross, tissue, cellular, protein and genetic levels, with such modelling and remodelling maintaining the integrity of oral structures vis-à-vis routine masticatory stresses. Ongoing integrative research using rabbit and rat models of long-term masticatory plasticity offers unique insight into the limitations of functional interpretations of fossilised remains. Given the general restriction of the palaeontological record to bony elements, we argue that failure to account for the disparity in the hierarchical network of responses of hard versus soft tissues may overestimate the magnitude of the adaptive divergence that is inferred from phenotypic differences. Second, we note that the developmental onset and duration of a loading stimulus associated with a given feeding behaviour can impart large effects on patterns of intraspecific variation that can mirror differences observed among taxa. Indeed, plasticity data are relevant to understanding evolutionary transformations because rabbits raised on different diets exhibit levels of morphological disparity comparable to those found between closely related primate species that vary in diet. Lastly, pronounced variation in joint form, and even joint function, can also characterise adult conspecifics that differ solely in age. In sum, our analyses emphasise the importance of a multi-site and hierarchical approach to understanding determinants of morphological variation, one which incorporates critical data on performance.
\end{abstract}

Key words: fossils, masticatory loading, musculoskeletal system, plasticity, mammals, skull, functional morphology, connective tissues, dietary properties, ontogeny.

\section{CONTENTS}

I. Introduction

II. Overview of diet-manipulation experiments

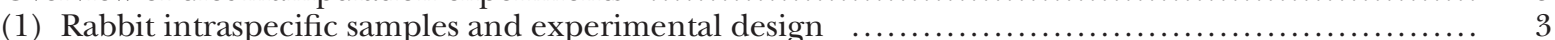

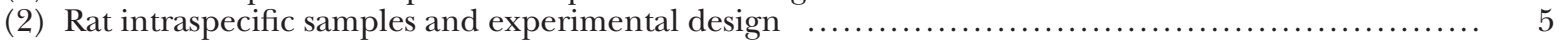

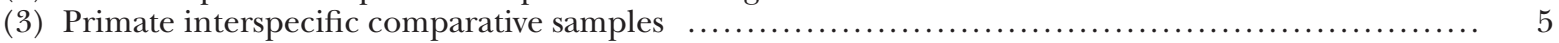

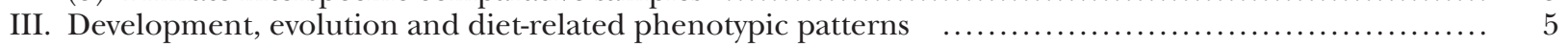

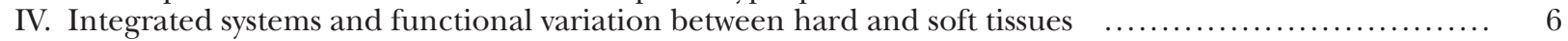

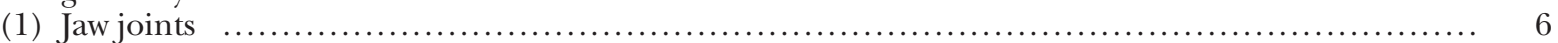

* Address for correspondence (Tel: 574-631-2556; Fax: 574-631-7413; E-mail: Matthew.J.Ravosa.1@nd.edu).

This is the author's manuscript of the article published in final edited form as: 


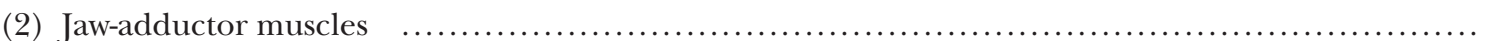

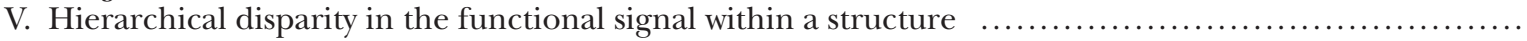

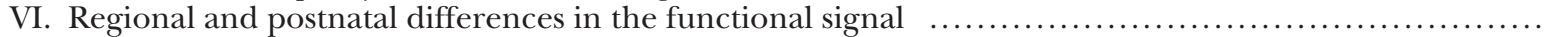

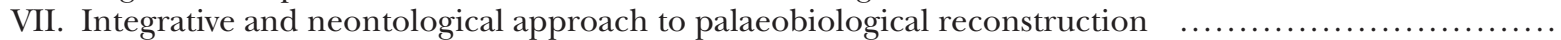

VIII. Conclusions

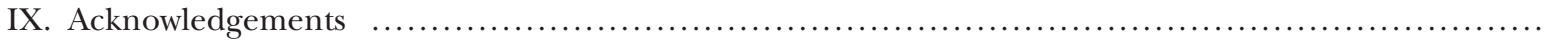

X. References

\section{INTRODUCTION}

Establishing the morphological adaptations and phylogenetic position of fossil species often hinges on our understanding of their behaviour and life history. Since hard tissues are highly mineralised, skeletal remains represent the primary means by which we determine the palaeobiology of extinct organisms. The information gleaned from such materials is considerable, being used to characterise a broad diversity of biological phenomena, including: $(i)$ evolutionary patterns of brain encephalisation, sensory development and sociality (Radinsky, 1977; Jerison, 1979; Martin, 1990; Bush, Simons \& Allman, 2004; Finarelli \& Flynn, 2009; Silcox, Dalmyn \& Bloch, 2009; Schultz \& Dunbar, 2010; Rowe, Macrini \& Luo, 2011; Steiper \& Seiffert, 2012); (ii) reconstructions of life history, ecology and climate-induced size change (Fleagle, 1985; Eisenberg, 1990; Roth, 1992; Raia \& Meiri, 2006; Secord et al., 2012); (iii) predator-prey coevolution, interspecific competition and guild composition (Fleagle, 1978; Maiorana, 1990; Ungar \& Kay, 1995; Schwartz, Rasmussen \& Smith, 1995); ( $i v)$ micro- and macroevolutionary patterns of size variation (Koch, 1986; Alroy, 1998; Gould \& MacFadden, 2004; Clauset \& Erwin, 2008; Smith et al., 2010; Raia et al., 2012; Steiper \& Seiffert, 2012); and (v) feeding and locomotor behaviour (Van Valkenburgh, 1982; Fleagle, 1985; Rose, 1990; Daegling \& Grine, 1991; Ravosa, 1991, 1996a,b, 1999; Janis, 1995). Such remarkable diversity of interests is not surprising, as bony elements are directly or indirectly involved in myriad biological phenomena.

Considerable interest in the biology of extinct vertebrates is exemplified by numerous studies directed at reconstructing functional diversity in the mammalian feeding complex. This focus is related to the adaptive and phylogenetic importance of variation in the oral cavity, coupled with the greater availability of well-preserved craniodental remains. In such cases, skeletal form is typically used to infer a given behaviour. Preferably, this functional association is based on a previously determined in vivo link between a specific feature and a given behaviour (Kay \& Cartmill, 1977; Lauder, 1995), thus potentially documenting the biological role of the structure or anatomical suite (Bock \& von Wahlert, 1965; Radinsky, 1985).

While a fossil occasionally preserves all or most of the skeletal information necessary for a comprehensive interpretation of past behaviours (e.g. White et al., 2009; Foth, Tischlinger \& Rauhut, 2014), evidence on joint function and musculoskeletal biomechanics is inevitably lost because such functional systems are not wholly composed of mineralised tissues (Ravosa et al., 2007a; Holliday et al.,
2010). In other cases, the fragmentary nature of fossil remains precludes a multifactorial perspective on complex morphological systems, such as the feeding apparatus. Perhaps due to the loss of information over time and associated taphonomic processes, the study of skeletal remains typically focuses on external aspects of morphological variation and less frequently applies a hierarchical perspective incorporating information on internal anatomy, microanatomy or cellular structure (Daegling \& Grine, 1991; Bush et al., 2004; Chinsamy-Turan, 2005; Schweitzer et al., 2005; Ravosa et al., 2007b; Villmoare \& Kimbel, 2011).

As fossil remains typically represent one tissue type from a (usually) incomplete structure, palaeontological analyses of functional systems that are hierarchically organised and composed of both hard and soft tissues present more difficulty as regards behavioural reconstructions. For nearly as long as workers have sought to reconstruct soft-tissue components of specific musculoskeletal systems, locomotor and feeding behaviour, as well as overall body size, there has been an awareness of the inherent difficulties and potential pitfalls of unravelling the functional attributes of extinct organisms (Kay \& Cartmill, 1977; Radinsky, 1982; Conroy, 1987; Damuth \& MacFadden, 1990; Jungers, 1990; Lauder, 1995; Smith, 2002). For instance, one analysis of extant strepsirrhine primates observed that molar size, often used to estimate body mass in fossils, can mispredict a species' body size by an average of $30 \%$ (Dagosto \& Terranova, 1992). While these fundamental concerns have prompted a number of detailed solutions for inferring function and behaviour from skeletal morphology (Kay \& Cartmill, 1977; Lauder, 1995; Witmer, 1995; Benton, 2010), it is also important to recognise and identify the various sources and corresponding levels of error in using hard tissues to infer the biology of extinct organisms.

Integrating data from a series of analyses focused on long-term diet-induced plasticity in the skull and feeding apparatus of growing rabbits (Ravosa etal., 2007a, 2008a,b, 2010a; Scott etal., 2014a,b) and rats (Menegaz, 2013), we highlight some of the inherent limitations of morphology-based interpretations of adaptation in extinct organisms. In doing so, we identify the kinds of approaches that might prove to be the most problematic and propose a series of integrative solutions to enhance the accuracy of functional inference. Our analyses underscore the utility of experimental investigations of plasticity for addressing questions regarding determinants of morphological variation, and contribute to the development of new approaches for interpreting evolutionary patterns of functional covariation in the vertebrate fossil record. 


\section{OVERVIEW OF DIET-MANIPULATION EXPERIMENTS}

\section{(1) Rabbit intraspecific samples and experimental design}

The white rabbit provides a unique opportunity to understand diet-induced plasticity in the mammalian masticatory apparatus. A major benefit of this animal model is that dynamic changes in feeding behaviours and loading regimes can be linked directly to post-weaning variation in the form, function and plasticity of craniomandibular elements. This is due to extensive in vivo data on jaw-adductor muscle activity, jaw kinematic and jaw loading patterns, masticatory function during ontogeny, intracortical remodelling, and the relationship between feeding behaviour and dietary properties (Weijs \& de Jongh, 1977; Weijs \& Dantuma, 1981; Weijs, Brugman \& Klok, 1987; Weijs, Brugman \& Grimbergen, 1989; Langenbach, Weijs \& Koolstra, 1991; Hirano et al., 2000; Langenbach et al., 2001; Langenbach \& van Eijden, 2001). Similar to observations in diverse groups of mammals, rabbit jaw-adductor muscle activity patterns vary with dietary properties (e.g. Herring \& Scapino, 1973; Gorniak \& Gans, 1980; Weijs et al., 1987, 1989; Dessem \& Druzinsky, 1992; Hylander, Johnson \& Crompton, 1992; Hylander et al., 2000), with increased jaw-adductor recruitment resulting in elevated peak strains and greater repetitive loading along the mandible (Weijs \& de Jongh, 1977; Hylander, 1979 a, b; Hylander et al., 1998; Ravosa et al., 2000). Further, work on dietary plasticity in rabbits is consistent with similar shorter-term experiments in other mammals (Beecher \& Corruccini, 1981; Bouvier \& Hylander, 1981, 1984, 1996; Beecher, Corruccini \& Freeman, 1983; Yamada \& Kimmel, 1991; He \& Kiliaridis, 2003; Lieberman et al., 2004; Ravosa et al., $2007 a$, 2008a,b).

The primary sources of evidence for comparisons presented herein are based on a series of experiments probing the role of dietary variation on the post-weaning development of musculoskeletal features in the skull of domestic New Zealand white rabbits (Oryctolagus cuniculus); in all such plasticity analyses, treatment groups consisted of 10 male subjects. The animal care facilities at which the rabbits were housed are USDA-licensed and AAALAC-accredited, with all procedures approved by respective Institutional Animal Care and Use Committees. Daily care of the experimental subjects, including monitoring of their health, was always performed by trained veterinary staff.

While some comparisons have been published elsewhere (Tables 1 and 2), these data are being compared and contrasted with recently collected unpublished data so as to provide new insights into the limits of morphological inference in the fossil record. This combination of static adult and more recent longitudinal data on the mechanobiology of rabbit craniofacial connective tissues is unparalleled among work on diet-induced plasticity in mammals and other tetrapods.

In all rabbit plasticity experiments performed to date, modification of food material properties began at weaning for several reasons (Ravosa et al., 2007a; Menegaz et al., 2009). First, it mitigates the effects of other loading influences that might confound comparisons among dietary cohorts. Second, given that organisms are thought to be differentially more susceptible to environmental cues earlier in postnatal development (Hinton \& McNamara, 1984; Meyer, 1987; Bouvier, 1988; Bertram \& Swartz, 1991; Rubin, Bain \& McLeod, 1992; Pearson \& Lieberman, 2004; Hoverman \& Relyea, 2007; Ravosa etal., 2008a; but see Scott et al., 2014b), it maximises the plasticity response to a diet-induced loading regime. Finally, as mammals begin to adopt adult diets and chewing behaviours around the time of weaning (Herring, 1985; Weijs et al., 1989; Langenbach et al., 1991, 2001; Iinuma, Yoshida \& Funakoshi, 1991; Westneat \& Hall, 1992), the commencement of dietary manipulation at such an early postnatal stage facilitates a more naturalistic experiment for comparison with variation observed in feral populations.

Apart from protocol duration (see below), variation in experimental design involved alteration of the presence/absence of hay cubes, combined with the uniform presence of rabbit pellets to ensure adequate nutrition (Table 1). Data on the material properties of intact pellets and hay cubes indicate that the latter is more mechanically challenging (i.e. tougher and with a higher elastic modulus) in terms of the forces and chewing cycles required for fragmentation along the postcanine dentition, thus

Table 1. Comparisons of experimental procedures and analyses

\begin{tabular}{|c|c|c|c|c|}
\hline Species & $\begin{array}{l}\text { Experiment length/ } \\
\text { subject age span }\end{array}$ & Experimental diets & Plasticity results presented herein & Relevant citations \\
\hline Rabbit \#1 & $\begin{array}{l}16 \text { weeks, } \\
\quad 4-20 \text { weeks old }\end{array}$ & Under-use, over-use & $\begin{array}{l}\text { Static data on external/internal } \\
\text { skeletal metrics, } \\
\text { biomineralisation }\end{array}$ & $\begin{array}{l}\text { Taylor et al. }(2006) \text {, Ravosa et al. } \\
\quad(2007 a, 2008 a, b) \text { and } \\
\text { Menegaz et al. }(2009,2010)\end{array}$ \\
\hline Rabbit \#2 & $\begin{array}{l}22 \text { weeks, } \\
4-26 \text { weeks old }\end{array}$ & $\begin{array}{l}\text { Under-use, over-use, } \\
\text { normal/control }\end{array}$ & $\begin{array}{l}\text { Static data on joint ossification, } \\
\text { metrics, biomineralisation, } \\
\text { cartilage histology, jaw-muscle } \\
\text { fibre type size and biochemistry }\end{array}$ & $\begin{array}{l}\text { Jašarević et al. }(2010), \text { Ravosa } \\
\text { et al. }(2010 a) \text { and M. Ravosa } \\
\text { (unpublished data) }\end{array}$ \\
\hline Rabbit \#3 & $\begin{array}{l}48 \text { weeks, } \\
\quad 4-52 \text { weeks old }\end{array}$ & $\begin{array}{l}\text { Normal/control, } \\
\text { annual/over-use, } \\
\text { seasonal (early/late) }\end{array}$ & $\begin{array}{l}\text { Longitudinal data on jaw } \\
\text { cross-sectional areas and } \\
\text { jaw-muscle mechanical advantage }\end{array}$ & $\begin{array}{l}\text { Scott et al. }(2014 a, b) \text { and M. } \\
\quad \text { Ravosa (unpublished data) }\end{array}$ \\
\hline Rat & $\begin{array}{l}12 \text { weeks, } \\
4-16 \text { weeks old }\end{array}$ & $\begin{array}{l}\text { Annual/over-use, } \\
\text { annual/under-use, } \\
\text { seasonal (early/late) }\end{array}$ & $\begin{array}{l}\text { Longitudinal data on mandibular } \\
\text { form and microstructure }\end{array}$ & $\begin{array}{l}\text { Menegaz (2013) and R. } \\
\text { Menegaz \& M. Ravosa } \\
\text { (unpublished data) }\end{array}$ \\
\hline
\end{tabular}


Table 2. Comparisons of adult jaw cross-sectional robusticity between primate sister taxa that vary in dietary proclivities and rabbits raised on different diets

\begin{tabular}{|c|c|c|c|c|}
\hline Group mean ratio & $\begin{array}{c}\text { Symphysis } 0.5 \\
\text { jaw length (\%) }\end{array}$ & $\begin{array}{c}\text { Palate }^{0.5} / \\
\text { jaw length }(\%)\end{array}$ & $\begin{array}{c}\text { Condyle }^{0.5} / \\
\text { jaw length }(\%)\end{array}$ & $\begin{array}{c}\text { Corpus }^{0.5} / \\
\text { jaw length (\%) }\end{array}$ \\
\hline \multicolumn{5}{|l|}{ Rabbits } \\
\hline Annual (= over-use) / control × 100 & 109 & 117 & 106 & 108 \\
\hline Annual (= over-use) $/$ seasonal $\times 100$ & 105 & 111 & 105 & 104 \\
\hline Seasonal/control $\times 100$ & 104 & 105 & 101 & 103 \\
\hline \multicolumn{5}{|l|}{ Primates } \\
\hline Cebus apella/Cebus capucinus $\times 100$ & 119 & - & - & 122 \\
\hline Gorilla gorilla / Pan troglodytes $\times 100$ & 96 & - & - & 98 \\
\hline Procolobus badius/Macaca fascicularis $\times 100$ & 102 & - & - & 104 \\
\hline Lophocebus albigena/Macaca fascicularis $\times 100$ & 99 & - & - & 112 \\
\hline
\end{tabular}

Percentages were calculated by dividing the mean ratio for the group with the more mechanically challenging diet by the mean ratio for the other group and multiplying by 100 . Corpus cross-sectional areas were obtained via computed tomography $(\mathrm{CT})$ at $\mathrm{M}_{2}$ in primates and via microCT at $\mathrm{P}_{4}$ in rabbits; while dietary effects on jaw length were minor in rabbits, the use of ratios controls for such factors in the analysis of diet on mandibular cross-sectional areas. Symphyseal sections were taken mid-sagittally in primates and coronally in rabbits. Mechanical differences in the primate pairwise dietary comparisons are well established: Cebus apella consumes harder and tougher objects more frequently than other species of Cebus (Daegling, 1992; Wright, 2005), Gorilla gorilla is more folivorous than Pan troglodytes (Tutin \& Fernandez, 1993; Taylor, Vogel \& Dominy, 2008) and, as compared to Macaca fascicularis, Procolobus badius is more folivorous while Lophocebus albigena processes hard objects more extensively (Daegling, 2002). Further details about the samples, measures and methods are elsewhere (great apes: Daegling, 2007; capuchins: Daegling, 1992; Old World monkeys: Daegling, 1993, 2002; rabbits: Scott et al., 2014a).

inducing elevated osteogenesis of masticatory structures (Ravosa et al., $2007 a$; Menegaz et al., 2009). Importantly, the material properties of the experimental foods fall within the range of values for diverse foods commonly exploited by primates in the wild (Williams etal., 2005). Our initial goal was to determine the broadest range of voluntary physiological responses to ad libitum oral processing of foods of different material properties and associated masticatory stresses. To this end, earlier analyses employed: ( $i$ ) a control diet of intact pellets representing a baseline range of loading and phenotypic variation; (ii) an under-use diet consisting of powdered rabbit pellets that required minimal mastication; and (iii) intact pellets supplemented daily with hay cubes to characterise an over-use diet with correspondingly elevated loading levels and greater cyclical loading (Ravosa et al., 2007a, 2008a,b, 2010a). All specimens were scanned post mortem using microcomputed tomography (microCT).

Recent work has attempted more closely to model dietary variation in the wild, including seasonal 'fallback foods', which are mechanically challenging items ingested during periods of resource scarcity (e.g. Terborgh, 1983; Wright, 2005). Thus, in contrast to the annual (= over-use) diet group, a seasonal diet group received hay cubes for only part of the experimental period (Scott et al., 2014a). Variability between seasonal and annual reliance on a challenging diet models the differences between 'filler' and 'staple' fallback foods (Marshall \& Wrangham, 2007) and potential variation in loading stimuli experienced by wild mammals. While it has been argued that cranial phenotypes are more labile earlier in development (Hinton \& McNamara, 1984; Meyer, 1987; Bouvier, 1988; Rubin et al., 1992; Ravosa et al., 2008b), the inclusion of early and late seasonal diet groups has been beneficial for showing that plasticity does not decrease uniformly with age (Scott et al., $2014 b)$. Rabbits in the early seasonal group each received three hay cubes daily for the first 6 weeks of the experimental period (i.e., post-weaning) and were then switched to an all-pellet diet for the following 18 weeks. This schedule was repeated in the second half of the experimental period. The other seasonal group, late seasonal, was subjected to the opposite feeding schedule; i.e. pellets only for the first 18 weeks, then hay cubes daily for the next 6 weeks, etc. In contrast to our prior static analyses of adult specimens imaged post mortem, longitudinal analysis of growing subjects was tracked via microCT. Subjects were scanned under anaesthesia upon arrival (week 0 ) and then biweekly thereafter for the first half of the experimental period (week 24) and then again following sacrifice (week 48), for a total of 14 postnatal ages (Scott et al., 2014a,b).

The broader significance of these analyses of diet-induced plasticity in rabbits is that they were carried out over a substantially longer period of (early) postnatal ontogeny than prior work on other mammals (Table 1) ( $c f$. Beecher \& Corruccini, 1981; Bouvier \& Hylander, 1981, 1984, 1996; Beecher et al., 1983; Yamada \& Kimmel, 1991; He \& Kiliaridis, 2003; Lieberman et al., 2004), which provides a more naturalistic modelling of dietary influences on an organism's life history. The basis for determination of developmental milestones is that in white rabbits, weaning occurs at about 4-5 weeks of age, with peak skeletal maturity attained at approximately 6 months old (Sorensen, Rogers \& Baskett, 1968; Yardin, 1974). The first study was carried out using rabbits raised for 3.4 months from weaning until subadulthood ( 4.5 months old) on either an under-use or over-use diet (Taylor et al., 2006; Ravosa et al., 2007a, 2008a,b; Menegaz etal., 2009, 2010). This static sample is the source of microCT-based comparisons of bone formation and biomineralisation in the mandibular symphysis discussed herein. Subsequent research extended the period of dietary manipulation to 5 months, expanding the treatment groups to under-use, control and over-use 
diets kept until adulthood (6 months old; Jašarević et al., 2010; Ravosa et al., 2010a). This static sample is the source of the following data: temporomandibular joint (TMJ) microCT, microCT on mandibular symphyseal fusion, TMJ articular cartilage histology, and masseter muscle fibre type histochemistry. The most recent work involved an experimental protocol that continued until the subjects were mature adults (1 year old), raising them 11 months from weaning on one of four diets: control, late seasonal, early seasonal or annual/over-use diets, as described above (Scott etal., 2014a,b). This sample is the source of longitudinal microCT data regarding the ontogeny of cross-sectional area of the palate, mandibular corpus and symphysis, as well as linear dimensions of masseter muscle mechanical advantage. The reader is directed to these publications for additional details on samples, imaging protocols, histological procedures, measurements and other analyses (Table 1).

\section{(2) Rat intraspecific samples and experimental design}

A longitudinal study of skeletal plasticity related to intra-individual variation in dietary properties was conducted using the Sprague-Dawley strain of laboratory rat (Rattus norvegicus) (Menegaz, 2013). This research examined morphological plasticity during post-weaning growth at both the macro- and micro-structural levels. Weekly in vivo microCT imaging combined with post mortem fluorescent histomorphometry was used to assess ontogenetic changes in mandibular morphology. Rats were obtained at weaning (21 days) and raised beyond skeletal maturity (12 weeks) into early adulthood (16 weeks). Each dietary treatment group consisted of 10 or 11 male subjects. Animal care facilities in which the rats were housed are USDA-licensed and AAALAC-accredited, with all procedures approved by Institutional Animal Care and Use committees. Further details on experimental design and analyses are located in Menegaz (2013).

Four dietary treatment groups were used in the rat study (Table 1). All groups were fed ad libitum comparable amounts of a rodent diet in either intact pellet or powdered pellet form. The use of the same diet presented in two different consistencies allowed for the modification of masticatory behaviour and the frequency/intensity of loading while offering comparable nutrition for all animals. Two 'annual' groups were fed a single diet for the duration of the experiment: an annual/over-use group, which was fed a diet of intact pellets; and an annual/under-use group, which was fed a diet of powdered pellets. Two 'seasonal' groups were fed a single diet (either intact or powdered pellets) for the first 6 weeks of the experimental periods, and then switched to the opposite diet for the last 6 weeks. The 'early' seasonal group was fed intact pellets for the first 6 weeks post-weaning, while the 'late' seasonal group was fed intact pellets for the last 6 weeks post-shift. The mid-experiment dietary shift, which occurred during the adolescent stage of rat ontogeny modelled a 'seasonal' shift in dietary composition, thus allowing for the evaluation of phenotypic plasticity during the optimal post-weaning growth period.

\section{(3) Primate interspecific comparative samples}

To underscore the relevance of intraspecific data on dietary plasticity for understanding interspecific or evolutionary variation in the mammalian feeding complex, rabbit microCT data on mandibular cross-sectional areas (corpus, symphysis) were compared to similar CT-based data for a series of pairwise analyses of primate sister taxa that vary in dietary properties (Daegling, 1989, 1992, 1993, 2002). To adjust for differences in jaw size among taxa and treatment groups, ratios of cross-sectional area versus mandibular length were calculated for these robusticity analyses. Our comparisons between rabbits and primates are employed to gauge empirically the magnitude of the morphological differentiation witnessed in long-term plasticity experiments vis-à-vis the metric disparity in mandibular cross-sectional area observed among adult wild-caught specimens. This contrasts the behavioural influence of diet properties in a protracted experimental setting to that experienced in a lifetime of species-specific feeding behaviours and attendant jaw-loading patterns. Additional information regarding the samples, CT imaging protocols and analyses are available elsewhere (Daegling, 1992, 1993, 2002, 2007).

\section{DEVELOPMENT, EVOLUTION AND DIET-RELATED PHENOTYPIC PATTERNS}

A number of workers have emphasised the importance of plasticity for understanding evolutionary change (Stearns, 1989; Gotthard \& Nylin, 1995; Agrawal, 2001; Pigliucci, 2001, 2005; West-Eberhard, 2003, 2005). One argument against intraspecific models of plasticity is that they do not generate comparable levels of morphological diversity as witnessed between sister taxa that vary in a given behaviour for an entire lifetime and which differ in history of adaptive genetic evolution. This criticism is untested largely because most plasticity studies examine biological phenomena over an extremely limited span of an organism's life history or during adult phases when reaction norms are thought to be lower or absent (Hinton \& McNamara, 1984; Meyer, 1987; Bouvier, 1988; Bertram \& Swartz, 1991; Rubin et al., 1992; Pearson \& Lieberman, 2004; Hoverman \& Relyea, 2007; Ravosa et al., 2008a; but see Scott et al., 2014b). Our analyses rectify this problem by inducing the onset of dietary divergence at weaning, when mammals typically adopt 'adult-like' jaw-adductor muscle and jaw-loading patterns (e.g. Herring, 1985; Weijs et al., 1989; Iinuma et al., 1991; Langenbach et al., 1991, 2001; Westneat \& Hall, 1992), and via the experimental modification of dietary properties for a longer-term, more naturalistic duration (i.e. typically from weaning through adulthood; Ravosa et al., 2010a; Scott et al., 2014a,b).

To explore the influence of diet on intra- and interspecific variation in jaw cross-sectional area, similar data are compared between rabbit cohorts and four sets of closely related primate species. Interestingly, while the disparity for mandibular cross-sectional areas is greater between capuchin (Cebus) species than among rabbit 
cohorts, the latter exhibit differences that equal or exceed sister-taxa differences in great apes and Old World monkeys (Table 2). Thus, despite the fact that the primate samples consisted of individuals that likely engaged in adult-like feeding behaviours for an appreciably longer portion of adulthood than in the rabbit samples, the magnitude of diet-induced variation in the mandible is equivalent at the intra- and interspecific levels (Daegling, 1989, 1992, 2002, 2007; Scott et al., 2014a,b). This suggests that dietary adaptive plasticity can contribute significantly to phenotypic variation observed between ecologically divergent species.

Another way plasticity can affect evolution is that altered reaction norms change the heritable variation upon which natural selection acts. Because plasticity influences phenotypic covariance structure, this can alter the way in which hereditary variation and selection interact to produce evolutionary change (Gupta \& Lewontin, 1982; Cheverud, Rutledge \& Atchley, 1983; Stearns, 1989). This means that the effects of diet-induced plasticity on cranial variance and covariance patterns will, in turn, alter the phenotypic response to natural selection. For example, lower facial structures in vertebrates are differentially affected by masticatory stresses and such factors can vary with size (Hylander, Picq \& Johnson, 1991; Bouvier \& Hylander, 1996; Hylander \& Johnson, 1997; Ravosa et al., 2000, 2010b; Ross \& Metzger, 2004; Menegaz et al., 2010). Thus, phenotypic covariation patterns will differ between lower and upper facial skulls for sister taxa that likewise differ in dietary properties, and these associations may vary allometrically.

\section{INTEGRATED SYSTEMS AND FUNCTIONAL VARIATION BETWEEN HARD AND SOFT TISSUES}

Plasticity is often viewed as adaptive in nature, informing us about functional patterns of morphological covariation (Stearns, 1989; Gotthard \& Nylin, 1995; Agrawal, 2001; Pigliucci, 2001, 2005; West-Eberhard, 2003, 2005). As emphasised previously (Kay \& Cartmill, 1977; Lauder, 1995), determination of specific functional associations in extant organisms is critical before a structure can be used to infer behaviour in the fossil record. This is especially important if a form or configuration can be linked uniquely to a given behaviour and thus has a particular biological role ( sensu Bock \& von Wahlert, 1965; Radinsky, 1985). Such criteria are potentially more difficult to uphold in the case of tissue composites such as joint and muscle systems, where only one component of a complex is amenable to fossilisation. The attendant challenges to this issue will be explored via a consideration of soft-/hard-tissue systems in the mammalian feeding apparatus, one related to load resistance and movement, and another related to force generation.

\section{(1) Jaw joints}

The temporomandibular joint (TMJ) of mammals is the bilateral articulation between the lower jaw and skull base, containing an articular disc interposed between articular
Table 3. Comparisons of temporomandibular joint (TMJ) external dimensions $(\mathrm{mm})$ and biomineralisation $(\mu)$ from adult rabbits raised on one of three different diets from weaning

\begin{tabular}{lccc}
\hline \hline Variable & $\begin{array}{c}\text { Under-use } \\
\text { mean }\end{array}$ & $\begin{array}{c}\text { Control } \\
\text { mean }\end{array}$ & $\begin{array}{c}\text { Over-use } \\
\text { mean }\end{array}$ \\
\hline Condyle AP length $(\mathrm{mm}) *$ & 11.800 & 12.037 & 12.473 \\
Condyle ML width $(\mathrm{mm})$ & 5.080 & 5.200 & 5.517 \\
Articular surface $(\mu)^{*}$ & 1.751 & 1.874 & 2.128 \\
Subchondral bone $(\mu) *$ & 1.966 & 2.125 & 2.390 \\
Condylar neck $(\mu)^{*}$ & 1.930 & 1.974 & 2.177 \\
\hline \hline
\end{tabular}

Anteroposterior (AP) and mediolateral (ML) measures of joint size were obtained using digital calipers whereas biomineralisation values were quantified with microCT. For most TMJ hard-tissue parameters, rabbits that routinely process a more mechanically challenging diet develop significantly larger and more mineralised condylar heads (ANOVA: $* P<0.05$ )

Adapted from Ravosa et al. (2010a).

surfaces. In the TMJ of rabbits subjected to elevated masticatory stress during biting and chewing of hay (Weijs \& de Jongh, 1977), there is a stereotypical adaptive response with members of the 'over-use' dietary cohort developing larger and more biomineralised condylar heads (Ravosa et al., 2007a, 2010a) (Table 3). By contrast, the expression of type II collagen and proteoglycans -extracellular matrix (ECM) proteins that confer soft-tissue viscoelasticity - is lower in the TMJ articular cartilage of rabbits raised on the same mechanically challenging diet (Ravosa et al., 2007a) (Fig. 1). This finding suggests that, because the TMJ is a tissue composite that functions to resist joint loads, a component of the long-term adaptive bony increase in condylar parameters compensates for diet-induced decreases in cartilage stiffness due to a reduction in ECM protein synthesis. Accordingly, one must temper conclusions about the strength of the adaptive signal in the TMJ, and perhaps the hard tissues of all joints for that matter, that follow from analyses concentrating on skeletal parameters. Put differently, in the absence of the soft-tissue data one would consistently overestimate the magnitude of the dietary influence on condylar form and, in turn, routinely misinterpret the extent to which different TMJ morphs in the palaeontological record reflect behavioural variation rather than related soft-tissue changes. Similar caution should be employed in neontological studies that base conclusions about joint function solely on protein expression in soft-tissue structures.

As the joint articular surface in fossils is usually incomplete due to the absence of cartilaginous remains (Ravosa et al., 2007a; Holliday etal., 2010) and taphonomic processes, this lack of evidence can also hinder an understanding of joint integrity, kinematics and kinetics. Clearly, further research is needed to identify better the softand hard-tissue contribution to joint performance and whether such tissue interactions vary with age, across skeletal regions and among species ( $c f$. Holliday et al., 2010). Of relevance is that there are limited data documenting an age-related divergence in bone architecture and bone quality between the TMJ and mandibular symphysis in the 
(A) Under-use

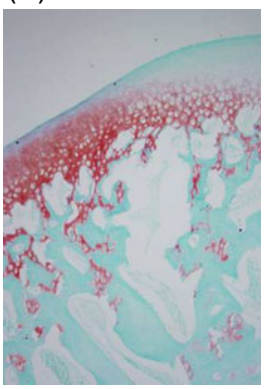

(B) Control

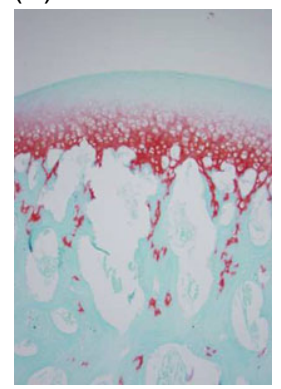

(C) Over-use diet

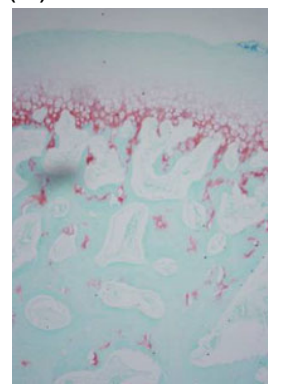

Fig. 1. Coronal histological sections of middle sites of the temporomandibular joint (TMJ) condyle articular surface from adult rabbits raised on one of three different diets $(A-C)$ from weaning (about $50 \times$ ). Sections were stained with safranin $O$ to characterise proteoglycan distribution. TMJ articular cartilage in 'over-use' rabbits shows lower proteoglycan content (i.e. decreased red staining intensity and distribution), which is indicative of reduced TMJ articular cartilage viscoelasticity. Thus, in contrast to hard tissues of the TMJ, rabbit TMJ articular cartilage routinely subjected to elevated loading due to a challenging diet experiences decreases in the ability to resist compressive loads during biting and chewing (adapted from Jašarević et al., 2010; see also Ravosa et al., 2007a, 2008b).

same mature adult rabbits (Ravosa et al., 2008a). Comparisons of proximal limb joints in growing pigs subjected to exercise-induced dynamic loading likewise indicate differences in bone and cartilage responses between the proximal humerus and proximal femur in the same experimental subjects (Congdon, Hammond \& Ravosa, 2012).

\section{(2) Jaw-adductor muscles}

Musculoskeletal units represent another functional system comprised of soft and hard tissues. The force-generating abilities of a given muscle include its mechanical advantage, which is tracked via bony attachment sites, the internal anatomy of the muscle itself (i.e. pinnation, fibre type, fibre size), and neuromotor factors such as compartmentalisation and spindle density. In a study of masseter muscle plasticity, rabbits raised on an 'over-use' diet developed a greater proportion of, and larger, type II muscle fibres (Fig. 2), both of which positively affect force-producing capabilities (Taylor et al., 2006; Ravosa et al., 2010a). However, analyses of the ontogeny of masseter mechanical advantage among rabbit dietary groups fails to detect any differences in the growth trajectories or terminal adult configurations (Fig. 3). This suggests that if one attempted to unravel the dietary correlates of masticatory form in rabbits based on jaw-adductor size and mechanical advantage, as is the case with fossils (e.g. DuBrul, 1977; Spencer \& Demes, 1993; Ravosa, 1996a; Friscia, Van Valkenburgh \& Biknevicius, 2007; Eng et al., 2013), it would have been impossible to infer most soft-tissue indicators of muscular function that covary with feeding behaviour.

This is not to say that variation in the soft and hard tissue components of a musculoskeletal unit cannot be detected between sister taxa, but rather that significant functional variation may be wholly unrecognised in those cases where
(A) Under-use diet

(B) Control diet

(C) Over-use diet

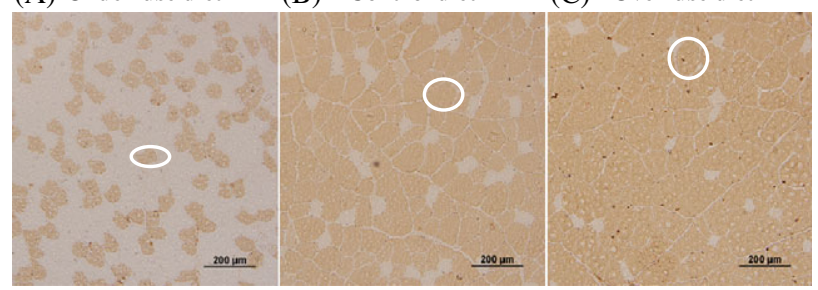

Fig. 2. Plasticity in fibre-type biochemistry and cross-sectional area for the intermediate region of the superficial masseter muscle in adult rabbits. In comparing the three dietary cohorts $(\mathrm{A}-\mathrm{C})$, note the trade-off in the relative abundance and size of type I (grey) versus type II (brown; encircled) muscle fibres, with over-use rabbits developing fewer, smaller type I fibres and more, larger type II fibres. Such increases in type II fibres facilitate the generation of faster and higher jaw-muscle forces during postcanine biting and chewing of a challenging diet, as well as likely explaining the presence of similar patterns of masseter muscle size increase across groups (adapted from Ravosa et al., 2010 a; see also Taylor et al., 2006).

the response is singularly or differentially muscular in nature. Thus, if using only skeletal parameters, one may underestimate the functional disparity between morphs that exhibit variation in the mechanical advantage of the jaw-adductor muscles. Biomechanical systems that effect movements consist of skeletal, muscular and neural components, all of which affect force generation and contraction velocity. However, as fossils only permit assessments of mechanical advantage, it will be necessary to evaluate more broadly if, and in what way, specific musculoskeletal units covary with a given oral function and whether such patterns vary among skeletal sites and across taxa.

\section{HIERARCHICAL DISPARITY IN THE FUNGTIONAL SIGNAL WITHIN A STRUCTURE}

A frequent goal of researchers working on fossils is to compare quantitative measures of skeletal form to similar parameters for extant close relatives and/or presumed functional analogs (Kay \& Cartmill, 1977; Lauder, 1995; Benton, 2010). Typically, this entails quantification of external bony dimensions, particularly for large interspecific samples (e.g. Ravosa \& Hogue, 2004). Such proportions, however, may not adequately reflect the biomechanical characteristics of a bony structure (Daegling \& Hylander, 2000). For instance, information on mandibular cortical bone geometry and distribution has been used to increase the accuracy of functional interpretations of feeding behaviour in extinct organisms (e.g. Daegling \& Grine, 1991). Since the performance of skeletal elements is dictated by a number of internal factors including bone quality, bone quantity and bone distribution, there remains the possibility that a functional signal may be differentially represented at one level of organisation versus another level. Indeed, such factors characterise diet-induced plasticity responses in the rabbit mandibular symphysis. 


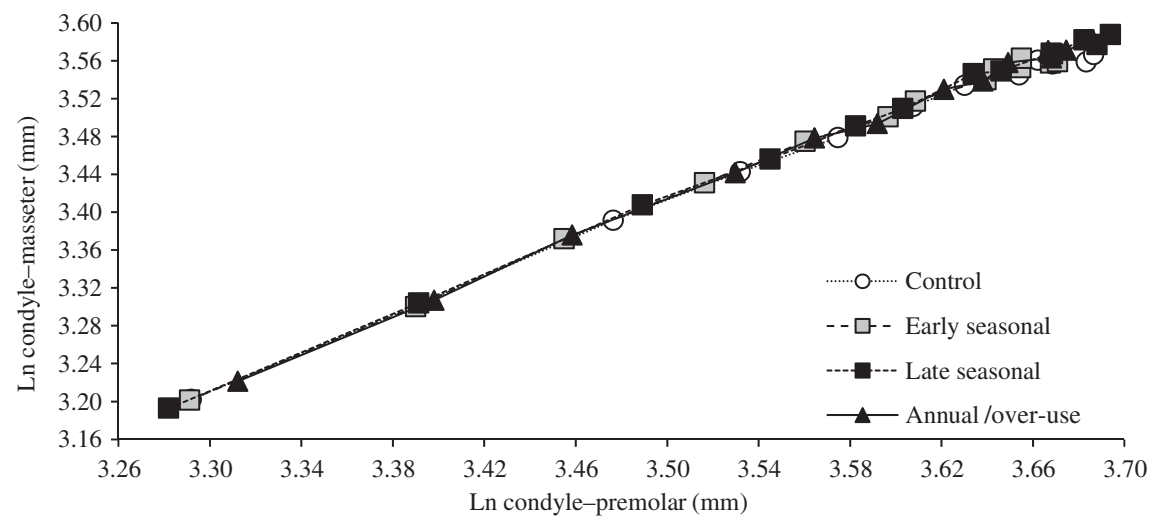

Fig. 3. Rabbit cranial growth allometries in four dietary cohorts raised from weaning through adulthood. MicroCT-based linear measures characterise the mechanical advantage of the superficial masseter muscle at the first premolar. Each datum represents a weekly group mean for each treatment group. Comparisons indicate that all dietary treatment groups exhibit similar ontogenetic trajectories and common terminal adult phenotypic configurations, suggesting the absence of functional differences in the mechanical advantage of the superficial masseter muscle.

Much like the TMJ, variation in the proportions and biomineralisation of the rabbit mandibular symphysis is associated with differences in the properties of foods processed during post-weaning development (Ravosa et al., $2007 a$ ). Interestingly, depending on whether one considers an external or internal joint dimension, the magnitude of the disparity between dietary groups varies and thus the apparent degree of dietary divergence. Internal dimensions such as cortical bone thickness, which are examined less frequently (but see Daegling, 1989, 1992, 1993, 2002), exhibit a greater disparity versus gross external dimensions more commonly used to track diet-related variation (e.g. Ravosa, 1991, 1996a; Ravosa \& Hogue, 2004; Wright, 2005; Friscia et al., 2007). In comparing external dimensions versus cortical bone thickness among rabbit dietary cohorts, the disparity is markedly greater for the internal dimensions (Table 4). Given that a number of biomechanical parameters are directly related to cortical bone thickness, this suggests that the use of external measures alone would underestimate the functional signal related to dietary properties, particularly as bone quality also varies between such dietary groups. Interestingly, the disparity in cortical bone biomineralisation between dietary groups is lower than that for cortical bone thickness, which suggests that variation in cortical bone distribution is potentially a more labile means of influencing functional variation in symphyseal morphology.

One aspect of symphyseal form that appears to be particularly sensitive to dietary variation in rabbits is the degree of joint fusion or ossification, which also varies with diet in diverse mammalian clades (Beecher, 1977, 1979; Scapino, 1981; Ravosa, 1991, 1996b, 1999; Ravosa \& Hogue, 2004; Scott, Hogue \& Ravosa, 2012a; Scott, Lack \& Ravosa, 2012b). Young rabbits typically exhibit a relatively simple mandibular symphysis that develops into a variably interdigitating or partially fused condition by adulthood with corresponding changes in the soft-tissue components (Hirschfeld, Michaeli \& Weinreb, 1977; Beecher, 1979). Remarkably, rabbits raised throughout post-weaning ontogeny on an 'over-use' diet
Table 4. Comparisons of symphyseal external proportions and biomineralisation values $(\mu)$ from subadult rabbits raised on one of two different diets from weaning

\begin{tabular}{lccc}
\hline \hline Variable & $\begin{array}{c}\text { Under-use } \\
\text { mean }\end{array}$ & $\begin{array}{c}\text { Over-use } \\
\text { mean }\end{array}$ & $\begin{array}{c}\% \\
\text { change }\end{array}$ \\
\hline Symphysis length ratio & 0.351 & 0.396 & $12.8^{*}$ \\
Symphysis width ratio & 0.129 & 0.148 & $14.7^{*}$ \\
Articular breadth ratio & 0.140 & 0.173 & $23.6^{*}$ \\
Superior cortex thickness ratio & 0.134 & 0.176 & $31.3^{*}$ \\
Lateral cortex thickness ratio & 0.058 & 0.089 & $53.4^{*}$ \\
Symphyseal surface $(\mu)$ & 1.668 & 2.024 & $21.3^{*}$ \\
Symphyseal cortex $(\mu)$ & 2.326 & 2.624 & $12.8^{*}$ \\
\hline \hline
\end{tabular}

Measures of joint size were obtained with digital calipers while biomineralisation was quantified via microCT. To adjust for subtle variation in overall skull size, ratios were calculated by dividing a measure of interest by cranial length. In all symphysis parameters, rabbits that regularly consume a more mechanically challenging diet develop significantly larger and more mineralised joints as well as thicker cortical bone. The column on the right presents the $\%$ mean difference based on the ratio of mean values for over-use versus under-use diet cohorts. Note that the magnitude of the disparity between diet groups is greater for cortical bone thickness than biomineralisation and symphysis external dimensions (ANOVA: $* P<0.05$ ).

Adapted from Ravosa et al. $(2007 a, 2008 b)$.

develop incipient ossification of the symphysis by adulthood (Fig. 4). Such diet-induced intraspecific variation tracks that typically observed above the genus level in various mammals (Ravosa, 1991, 1996b, 1999; Ravosa \& Hogue, 2004; Scott etal., 2012a,b). Indeed, if considered in the absence of additional data from the feeding apparatus of the rabbit samples (i.e. fragmentary and out of context, much like most fossil specimens), the observed pattern of accelerated developmental onset of symphyseal fusion would seemingly represent a macroevolutionary or heterochronic event rather than a diet-induced reaction norm within a single species. Similar work on locomotor plasticity in a ray-finned fish capable of facultative terrestriality 

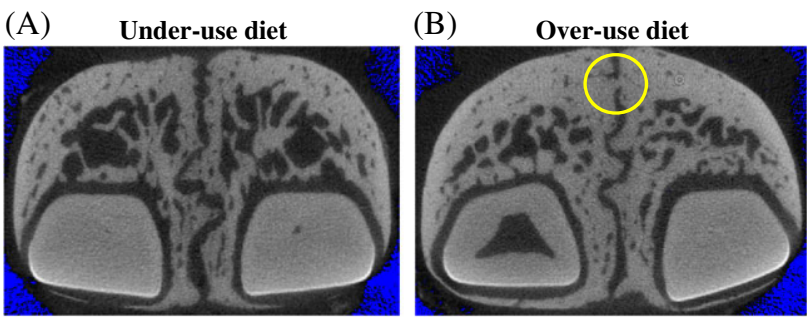

Fig. 4. Coronal microCT sections of middle symphyseal sites from adult rabbits raised on different diets from weaning (about $5 \times$ ). At the top of the image in (B), note the encircled part of the joint spanned by bone. This synostosis alters joint function by increasing symphysis strength during mastication and differs significantly from the configuration in (A) for the other diet cohort, where the strength of such a synarthrosis is more dependent on variation in soft-tissue properties.

(Polypterus senegalus) showed that subjects raised in a terrestrial environment developed changes in the pectoral girdle mirroring those changes characteristic of the transition between the earliest tetrapods and their aquatic ancestors (Standen, Du \& Larsson, 2014).

In another recent study with implications for palaeobiological interpretations, variation in metacarpal form among living apes and humans is utilised to predict locomotor and manipulative behaviours in australopiths (Skinner etal., 2015). Of particular importance is the incorporation of data on patterns of trabecular bone distribution that affords a new source of morphological information undetected in prior analyses of external anatomy. Nonetheless, such inferences would benefit greatly from experimental research regarding the ontogeny and plasticity of cancellous bone architecture in metacarpals subjected to the range of behavioural variation witnessed across extant hominoids.

As there is a paucity of work regarding how postnatal changes in loading stimuli affect bone properties in the mammalian skull, it is not surprising that few palaeontological studies have examined variation in fossil microstructural properties (e.g. Ravosa etal., 2007b). Fortunately, there is considerably more information on the postcranium. Analysis of bone cross-sectional geometry, bone mechanical properties, and tissue composition in the mouse tibia revealed that exercise can elicit alterations in bone composition and structural integrity without changes in bone geometry (Kohn et al., 2009; Wallace, Ron \& Kohn, 2009; Wallace et al., 2010). Thus, exercise significantly increased tibial strength in the absence of bone formation, with improved skeletal performance due only to an altered mineralised matrix. These findings further stress the importance of a hierarchical assessment of reaction norms, coupled with the need to evaluate the performance of such load-induced changes. As there was no plasticity response to altered loads at a gross anatomical level between mouse treatment groups, one might assume that skeletal performance was also similar, much as would be the case based on traditional analyses of cortical bone geometry. Only in detecting a notable difference in tibial bending strength was it then determined that exercise induced finer-scale plasticity in bone mineral content independent of variation in other parameters that influence skeletal function. Clearly, adaptive variation in bone quality, architecture and geometry can develop independently of one another, with evidence of a behaviour-induced signal and consequent influences on skeletal performance overlooked if multiple levels of bony organisation are not considered.

\section{REGIONAL AND POSTNATAL DIFFERENCES IN THE FUNCTIONAL SIGNAL}

Palaeobiology aims to reconstruct the behaviour of fossil organisms. In such cases, it is typically assumed that the ultimate form reflects the intra-individual ontogeny of behavioural influences on bone formation (e.g. Heinrich, Ruff \& Weishampel, 1993), that variance in tissue responses among adjacent regions under similar functional influences is minimal, and that plasticity decreases with age (see Section II.1). A longitudinal perspective on postnatal dietary shifts among rabbit cohorts provides evidence to the contrary. Annual and early seasonal rabbits raised from weaning on a similar 'over-use' diet exhibit similar growth patterns for three jaw measures, which differs from that of a control group raised on a baseline diet of only rabbit pellets (bootstrap test; Scott et al., 2014a). When the early seasonal group is switched to a pellets-only diet, it develops adult proportions for palate, symphysis and corpus cross-sectional areas that are not statistically distinguishable from the control group and significantly lower than those for the over-use/annual group (bootstrap test; Fig. 5; Scott etal., 2014a). This is much as would be predicted based on its intermediate postnatal loading history. Since adult proportions for the early seasonal group are indistinguishable from those of the control group (Fig. 5), these latter results are particularly interesting as the adult proportions in 'early seasonal' rabbits reflect no signal whatsoever about earlier behavioural influences, when this cohort experienced the same over-use loading stimuli as the annual group. If only adult patterns of morphological variation were sampled, which replicates the conditions for most extant and extinct comparative analyses, one would not be able to recover the 'seasonal' shift in diet-induced loading signal. Rather, similar behaviours would have been inferred incorrectly as underlying the phenotypes of early seasonal and control rabbits.

Simultaneously vexing and intriguing is that among masticatory elements in the same organisms subjected to the same loading regimes, functional responses nonetheless vary, and the corresponding signal differs depending on the onset and perhaps sequence of loading events ( $c f$. Menegaz, 2013; Scott et al., 2014a). Within-element variation in the osteogenic responses to elevated loads between the femoral diaphysis and metaphysis has also been observed in mice subjected to differing levels of treadmill exercise (Hamrick et al., 2006). Emerging evidence further indicates that age-related decreases in plasticity might vary among skeletal regions and across taxa (Scott et al., 2014b). 

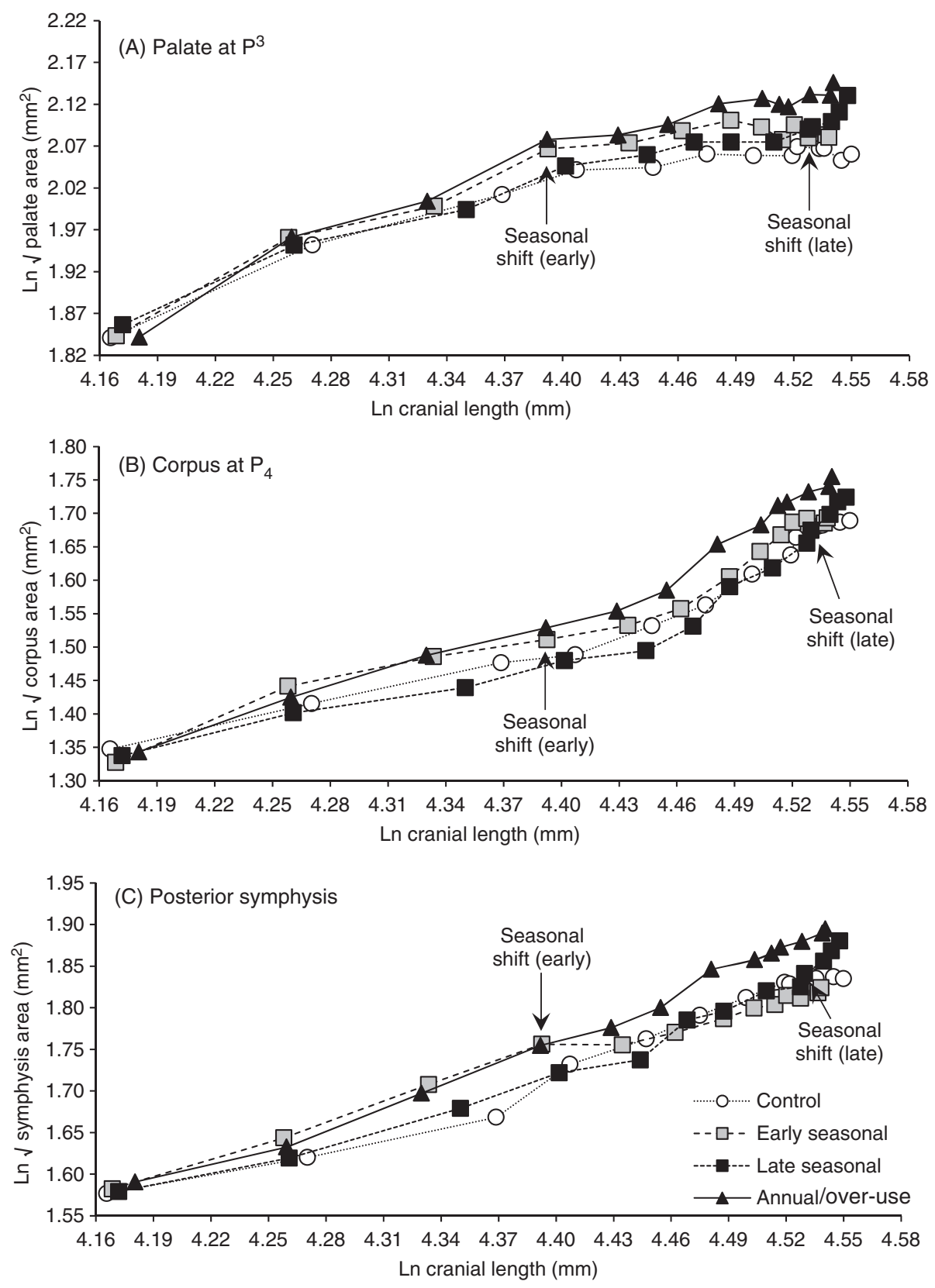

Fig. 5. Post-weaning rabbit jaw growth in four dietary cohorts raised until adulthood. MicroCT-based measures of bone cross-sectional area ${ }^{0.5}$ versus mean cranial length: (A) palate, (B) corpus, and (C) symphysis. Each datum represents a weekly group mean. Note that the trajectories of the early seasonal group are similar to those of the annual/over-use group until the seasonal shift in diet. Subsequently, the early seasonal group's trajectories converge on those for the control group. In other words, the terminal adult phenotype of the early seasonal cohort reflects only the most recent behavioural impact of the control diet (adapted from Scott et al., 2014a).

Rabbits subjected to a shift to a mechanically challenging diet around the time of skeletal maturity (late seasonal group) exhibited an unexpectedly strong plastic response, similar to that observed in the rabbit cohort given the same diet just after weaning (early seasonal). This indicates that young adults can be as susceptible to environmental conditions as juveniles (Scott et al., 2014b; Fig. 5). Arguably, an under-appreciation of intrinsic regional variation in the sensitivity of connective tissues to external stimuli is due to a currently pervasive, site-specific perspective on skeletal form and function (see also Hsieh et al., 2001).

A study of dietary seasonality in a different mammalian model, the laboratory rat, also found ontogenetic variance in tissue responses among adjacent regions subjected to the same loading regimes (Menegaz, 2013). In adult rats that had undergone one 'seasonal' shift mid-adolescence, osseous mandibular morphologies within close proximity were found to differentially reflect dietary treatments. For 


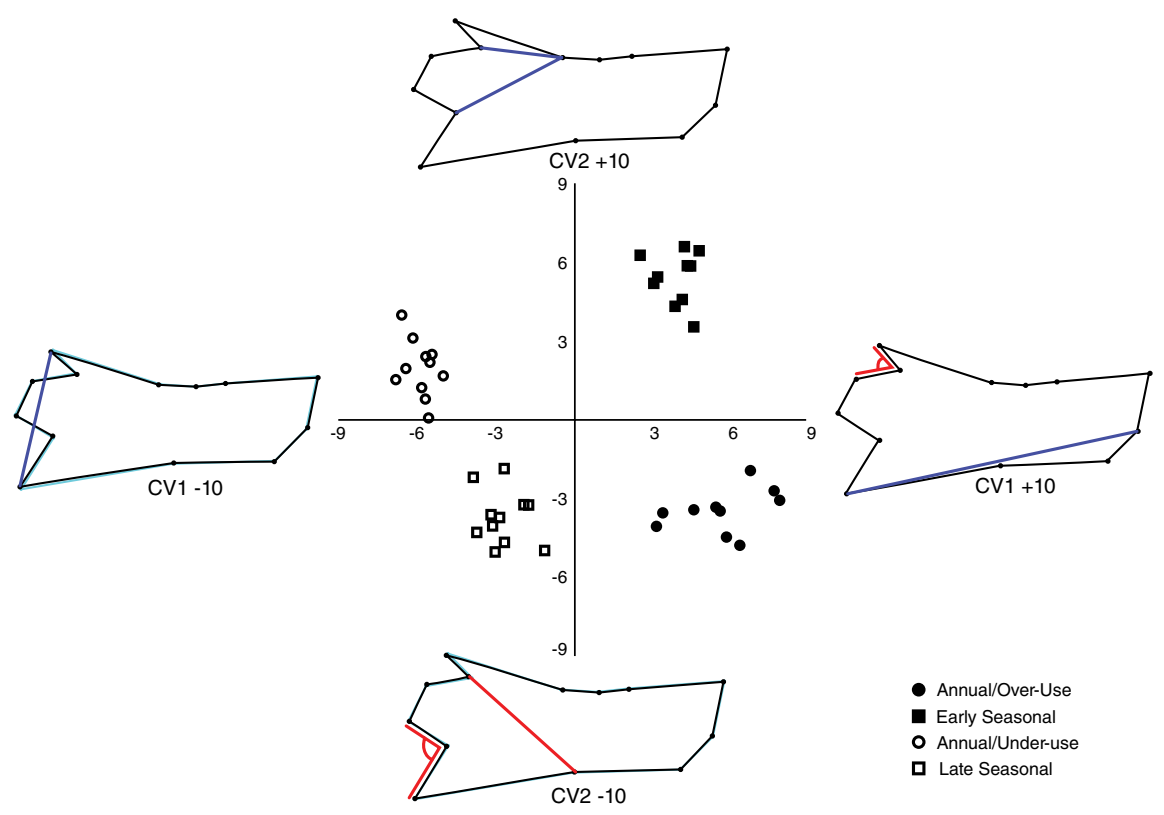

Fig. 6. Results of a canonical variates analyses of three-dimensional mandibular morphology in adult rats (adapted from Menegaz, 2013). The $x$-axis is canonical variate 1 (CV1), the $y$-axis is CV2. CV1 groups individuals by their early diet, and describes changes in mandibular length and coronoid process morphology. CV2 groups individuals by their late diet, and describes changes in angular process and masseteric fossa morphology. Wireframe mandibles represent the shape changes at either $+10 /-10$ along their respective CVs. Red lines indicate an increasing linear or angular dimension; blue lines represent a decreasing linear or angular dimension.

example, animals subjected to an early seasonal 'over-use' diet were most similar to those raised on an annual 'over-use' diet in mandibular length and in features related to the coronoid process, while subjects with a late seasonal 'over-use' diet were most similar to those raised on an annual 'over-use' diet in features related to the angular process and masseteric fossa (Fig. 6). Despite their close proximity and common function as attachment sites for masticatory muscles, these structures - the coronoid and angular processes - produced disparate 'ecological' signals even within a single individual raised on a seasonal diet. Furthermore, in immature rats that had not yet undergone a 'seasonal' dietary shift, it was considerably more difficult to distinguish between subjects in the 'over-use' versus 'under-use' groups. This was due to the fact that the majority of morphological variance in these younger individuals was concentrated in the mandibular corpus, reflecting the overarching importance of dental eruption and formation during this stage of ontogeny (Menegaz, 2013).

In addition to these regional differences in macrostructural skeletal plasticity, Menegaz (2013) also observed regional variation in microstructural processes. Adjacent regions, such as the molar and incisal portions of the mandibular corpus, exhibited different responses in mineral apposition rates to the experimental dietary shift. Larger mandibular regions, such as the ramus and the corpus, varied in the timing of the transition from bone modelling to remodelling as the dominant physiological process. In sum, data from both our rabbit study and a similar study of rats (Menegaz, 2013) emphasises that - in the presence of simulated dietary seasonality - the ecomorphological signal derived from craniomandibular morphology is largely dependent on the specific anatomical feature under study as well as the age of the individual.

\section{INTEGRATIVE AND NEONTOLOGICAL APPROACH TO PALAEOBIOLOGICAL RECONSTRUCTION}

The comparisons provided herein serve to underscore the limits in our ability to employ morphological data for reconstructing the behaviour of extinct organisms. While acknowledging that some issues are intractable (e.g. preservation, taphonomy), nonetheless they draw attention to potential approaches that one might use to minimise problems with morphological inference. As advanced by previous workers, an integrative perspective is clearly warranted, one informed by experimental and ecomorphological analyses of biological systems for understanding the fossil record and associated evolutionary transformations in a clade. We further advocate hierarchical and multifactorial analyses of determinants of morphological variation in complementary hard- and soft-tissue components as well as the need to consider all functional aspects of skeletal architecture, such as cortical and trabecular bone as well as bone quality (i.e. ultrastructure, material properties). While it is often assumed that morphological differences among taxa are indicative of 
functional variation, it is requisite to examine the performance of a given structure or system vis-à-vis multiple skeletal parameters. As bone is hierarchically organised and responds adaptively to mechanical stimuli on multiple levels, elevated bone formation is only one mechanism of increasing bone strength. It is unlikely that the singular use of external skeletal dimensions will furnish the requisite evidence for accurate palaeobiological reconstructions.

While not a primary focus of this discussion, our observations have direct implications for the increasingly common use of finite element analysis (FEA) in functional studies of diverse vertebrate fossils (e.g. Dumont, Piccirillo \& Grosse, 2005; Strait et al., 2009; Young et al., 2012; Gill et al., 2014). While it has been acknowledged that there are limits to accurate modelling of dynamic jaw-loading regimes in extinct organisms (Richmond et al., 2005; Young et al., 2012), our analyses highlight additional challenges with the current application of such methods. The presence of significant variation in tissue mineral density within and between masticatory elements (see Tables 3 and 4), which greatly affects bone properties and skeletal performance independent of cortical bone quantity (Kohn et al., 2009; Wallace et al., 2009, 2010), undermines widespread assumptions about homogeneity of tissue properties in FEA models of fossil crania. Indeed, the underlying regional, hierarchical and ontogenetic complexity of biological systems highlights the inherent problems with applying FEA to extinct organisms. For similar reasons, approaches utilising geometric morphometrics exclusively are ill-suited to the analysis of function in fossil vertebrates (e.g. Brusatte et al., 2012; van Heteren et al., 2014; but see Cornette et al., 2013, for an integrative perspective on musculoskeletal covariation in the masticatory system).

Barring information on biological roles of systems, bone properties and site-specific tissue responses of extant analogs, it would be premature to assume that in silico models of musculoskeletal function in extinct taxa can offer us reliable insights into functional and behavioural variation, much less adaptation, in the fossil record. Rather than filling a gap in our understanding of determinants of variation in a given anatomical complex, such analyses introduce assumptions that can considerably oversimplify physiological characterisation of the system of interest, especially when variation in internal skeletal anatomy is disregarded. In addition, the dynamic nature of bone metabolic activity is neglected, and instead stress fields are characterised and compared under the assumption that the form of these stress fields permits inference of behavioural adaptation. Arguably, the eventual utility of computer-based functional models of fossil specimens would profit from significantly greater efforts directed first at laboratory- and field-based research on how individual components of an integrated and hierarchically organised biological system contribute to phenotypic variation in performance (Vinyard, Yamashita \& Tan, 2008; Yamashita, Vinyard \& Tan, 2009). Applications of such models to ontogenetic processes of skeletal modelling and remodelling show great promise (Carter \& Beaupré, 2001).

A common conclusion drawn from our findings is that morphology-based analyses of behaviour based on a single anatomical region or type of data, particularly gross dimensions (a common approach in palaeontology), are the most likely to be misleading. This highlights the importance of a hierarchical and multifactorial perspective for addressing the functional characterisation of tissue composites. Such a framework will aid in understanding how individual components of an integrated biological system contribute to phenotypic variation in performance (e.g. Ravosa etal., $2007 a$; Kohn etal., 2009; Wallace et al., 2009, 2010). For instance, in vivo and ex vivo analyses of tree-gouging behaviour, jaw form and symphyseal performance in gouging versus non-gouging New World monkeys indicate a number of TMJ, anterior dental and jaw-muscle features unique to gouging marmosets. However, tests of symphyseal bending and shear strength indicate that this region is under-constructed for resisting loads vis-à-vis non-gouging sister taxa, which implies the presence of functional trade-offs (Hogg et al., 2011; Vinyard et al., 2011; see also Hylander \& Johnson, 1997, regarding in vivo strain and the functional morphology of the zygomatic arch). Likewise, the variable contribution of epiphyseal cartilage to archosaur long bones underscores inherent difficulties in reconstructing joint congruence, posture and range of motion in the locomotor apparatus of dinosaurs (Holliday etal., 2010). Although researchers attempt to derive the most parsimonious explanation for biological phenomena, usually via a limited number of variables, the inclusion of additional evidence has the potential to result in greater accuracy in palaeobiological scenarios regarding feeding behaviour and dietary adaptations in the vertebrate fossil record.

\section{CONCLUSIONS}

(1) Although previously unappreciated, the magnitude of the within-species plasticity response to long-term dietary manipulation can vary to the same extent as witnessed between sister taxa that differ in feeding behaviour. Our work indicates that the role of plasticity is potentially on a par with natural selection in affecting patterns of phenotypic covariation and variation within and across species. Taken a step further, determination of species status based on masticatory features subject to functional variation can be problematic when applied to fossil remains.

(2) Hard and soft tissues respond differently to mechanical stimuli and thus impart different functional signals. This likely reflects the integrated and compensatory nature of such biological systems. As studies of fossil joints and muscle mechanics directly consider only the bony component, it is important to detail how phenotypic variation in that component tracks functional variation in the entire system.

(3) The adaptive signal to a loading pattern can vary hierarchically within and across bony elements. As skeletal parameters and sites respond differently to altered mechanical stimuli, they will convey different signals for behavioural reconstructions. Our analyses also note the presence of regional variation in intrinsic factors such as 
biomineralisation. If solely skeletal in nature, comparative analyses can only track one aspect of an organism's functional morphology. Thus, palaeobiological reconstructions relying on a limited number of parameters have a greater likelihood of being inaccurate. It is imperative that one determines the strength of a functional signal obtained with fossil remains, the extent to which it varies within and among skeletal sites, and how specific bony parameters relate to the performance of a given structure or system.

(4) Musculoskeletal form, function and behaviour can change ontogenetically, even in adults. For these reasons, loading history inferred from adult form, including significant osteogenic events, can be obscured by subsequent behavioural shifts. As the ability to respond plastically varies across taxa, ages and anatomical sites (Scott et al., 2014b), morphological variation among adult specimens may reflect an amalgam of adult and juvenile influences on a system of interest. This can hinder the ability to recover information about skeletal function from fossil remains. Indeed, studies of immature organisms can recover different - and sometimes less ecologically informative - signals as compared to adults (Holmes \& Ruff, 2011; Menegaz, 2013).

(5) Intraspecific phenotypic variation related to functional differentiation has the potential to be misinterpreted as non-homologous and macroevolutionary in nature. Therefore, evaluating the functional and ecological determinants of character-state variation is central to considerations of homology in phylogeny reconstructions that incorporate fossil remains.

(6) We advocate a neontological solution to the unique challenges posed by fossils, one informed by the palaeontological record so as to identify the biological system(s) of greatest relevance to understanding evolutionary transformation in a clade. Such an approach should be inherently integrative, including hierarchical and multifactorial analyses of determinants of morphological variation in hard-and soft-tissue components, as well as myriad aspects of musculoskeletal architecture and functional organisation. To the extent possible, these investigations should be longitudinal, exploring complex in vivo patterns of developmental and functional covariation (e.g. Dodson, $1975 a, b$; Bernays, 1986; Erickson, Lappin \& Vliet, 2003; Scott et al., 2014a).

\section{ACKNOWLEDGEMENTS}

M. Leevy, S. Stock, J. Ning, A. Daniel, R. Kunwar, M. Eastman and S. Stack assisted with aspects of data collection and analysis. E. Franks, A. Remer, K. Thompson and two anonymous reviewers provided comments on this manuscript. We thank the staff of Freimann Life Science Center, especially M. Suckow, K. Stewart, V. Mack, V. Schroeder, B. Pogotis, and A. Sipocz, for help with recent experimental subjects. Funding was obtained from the NSF to M.J.R. (BCS-1029149/1214767 and BCS-0924592/1214766), NSF to R.A.M. and M.J.R. (BCS-1061368), and Wenner-Gren Foundation and American Society of Mammalogists to R.A.M.

\section{REFERENCES}

Agrawal, A. A. (2001). Phenotypic plasticity in the interactions and evolution of species. Science $\mathbf{2 9 4}, 321-326$.

Alroy, J. (1998). Cope's Rule and the dynamics of body mass evolution in North American fossil mammals. Science 280, 731-734.

BEEcher, R. M. (1977). Function and fusion at the mandibular symphysis. American Journal of Physical Anthropology 47, 325-336.

BeEcher, R. M. (1979). Functional significance of the mandibular symphysis. Journal of Morphology 159, 117-130.

BeEcher, R. M. \& Corruccini, R. S. (1981). Effects of dietary consistency on craniofacial and occlusal development in the rat. Angle Orthodontist 51, 61-69.

Beecher, R. M., Corruccini, R. S. \& Freeman, M. (1983). Craniofacial correlates of dietary consistency in a nonhuman primate. Journal of Craniofacial Genetics and Developmental Biology 3, 193-202.

Benton, M. J. (2010). Studying function and behavior in the fossil record. PLoS Biology 8, e1000321.

BernaYs, E. A. (1986). Diet-induced head allometry among foliage-chewing insects and its importance for graminivores. Science 231, 495-497.

Bertram, J. E. \& Swartz, S. M. (1991). The 'law of bone transformation': a case of crying Wolff? Biological Reviews 66, 245-273.

Bock, W. J. \& von WAhlert, G. (1965). Adaptation and the form-function complex. Evolution 19, 269-299.

Bouvier, M. (1988). Effects of age on the ability of the rat temporomandibular joint to respond to changing functional demands. Journal of Dental Research $\mathbf{6 7}$, 1206-1212.

Bouvier, M. \& Hylander, W. L. (1981). Effect of bone strain on cortical bone structure in macaques (Macaca mulatta). Journal of Morphology 167, 1-12.

Bouvier, M. \& Hylander, W. L. (1984). The effect of dietary consistency on gross and histologic morphology in the craniofacial region of young rats. American Journal of Anatomy 170, 117-126.

Bouvier, M. \& Hylander, W. L. (1996). Strain gradients, age, and levels of modeling and remodeling in the facial bones of Macaca fascicularis. In The Biological Mechanisms of Tooth Movement and Craniofacial Adaptation (eds Z. Davidovitch and L. A. Norton), pp. 407-412. Harvard Society for the Advancement of Orthodontics, Boston.

Brusatte, S. L., Sakamoto, M., Montanari, S. \& Harcourt Smith, W. E. (2012). The evolution of cranial form and function in theropod dinosaurs: insights from geometric morphometrics. Journal of Evolutionary Biology 25, $365-377$.

Bush, E. C., Simons, E. L. \& Allman, J. M. (2004). High-resolution computed tomography study of the cranium of a fossil anthropoid primate, Parapithecus grangeri: new insights into the evolutionary history of primate sensory systems. Anatomical Record 281A, 1083-1087.

CARTER, D. R. \& BeAupré, G. S. (2001). Skeletal Form and Function: Mechanobiology of Skeletal Development, Aging and Regeneration. Cambridge University Press, Cambridge.

Cheverud, J. M., Rutledge, J.J. \& Atchley, W. R. (1983). Quantitative genetics of development: genetic correlations among age-specific trait values and the evolution of ontogeny. Evolution 37, 895-905.

Chinsamy-Turan, A. (2005). The Microstructure of Dinosaur Bone-Deciphering Biology through Fine Scale Techniques. Johns Hopkins University Press, Baltimore.

Clauset, A. \& Erwin, D. H. (2008). The evolution and distribution of species body size. Science 321, 399-401.

Congdon, K. A., Hammond, A. S. \& Ravosa, M. J. (2012). Differential limb loading in miniature pigs (Sus scrofa domesticus): a test of chondral modeling theory. Journal of Experimental Biology 215, 1472-1483.

Conroy, G. C. (1987). Problems of body-weight estimation in fossil primates. International Journal of Primatology 8, 115-137.

Cornette, R., Baylac, M., Souter, T. \& Herrel, A. (2013). Does shape co-variation between the skull and the mandible have functional consequences? A 3D approach for a 3D problem. Journal of Anatomy 223, 329-336.

DaEgling, D. J. (1989). Biomechanics of cross-sectional size and shape in the hominoid mandibular corpus. American Journal of Physical Anthropology 80, $91-106$.

Daegling, D. J. (1992). Mandibular morphology and diet in the genus Cebus. International Journal of Primatology 13, 545-570.

Daegling, D. J. (1993). The relationship of in vivo bone strain to mandibular corpus morphology in Macaca fascicularis. Journal of Human Evolution 25, $247-269$.

DAegling, D. J. (2002). Bone geometry in cercopithecoid mandibles. Archives of Oral Biology 47, 315-325.

Daegling, D. J. (2007). Relationship of bone utilization and biomechanical competence in hominoid mandibles. Archives of Oral Biology 52, 51-63.

Daegling, D. J. \& Grine, F. E. (1991). Compact bone distribution and biomechanics of early hominid mandibles. American Journal of Physical Anthropology 86, 321-339. 
Daegling, D. J. \& Hylander, W. L. (2000). Experimental observation, theoretical models and biomechanical inference in the study of mandibular form. American Journal of Physical Anthropology 112, 541-551.

Dagosto, M. \& Terranova, C. J. (1992). Estimating the body size of Eocene primates: a comparison of results from dental and postcranial variables. International Journal of Primatology 13,07-344.

Damuth, J. \& MacFadden, B. J. (1990). Introduction: body size and its estimation. In Body Size in Mammalian Paleobiology (eds J. Damuth and B. J. MacFadden), pp. 1-10. Cambridge University Press, Cambridge.

Dessem, D. \& Druzinsky, R. E. (1992). Jaw-muscle activity in ferrets, Mustela putorius furo. Journal of Morphology 213, 275-286.

Dodson, P. (1975a). Relative growth in two sympatric species of Sceloporus. American Midland Naturalist 94, 421-450.

Dodson, P. $(1975 b)$. Taxonomic implications of relative growth in lambeosaurine hadrosaurs. Systematic Zoology 24, 37-54.

DuBrul, E. L. (1977). Early hominid feeding mechanisms. American Journal of Physical Anthropology 47, 305-320.

Dumont, E., Piccirillo, J. \& Grosse, I. (2005). Finite-element analysis of biting behavior and bone stress in the facial skeletons of bats. Anatomical Record 283A, 319-330.

EisenberG, J. F. (1990). The behavioral/ecological significance of body size in the Mammalia. In Body Size in Mammalian Paleobiology (eds J. Damuth and B. J. MacFadden), pp. 25-37. Cambridge University Press, Cambridge.

EnG, C. M., Lieberman, D. E., Zink, K. D. \& Peters, M. A. (2013). Bite force and occlusal stress production in hominin evolution. American Journal of Physical Anthropology 151, 544-557.

Erickson, G. M., Lappin, A. K. \& Vliet, K. A. (2003). The ontogeny of bite-force performance in American alligator (Alligator mississippiensis). Journal of Zoology (London) 260, 317-327.

Finarelli, J. A. \& Flynn, J. J. (2009). Brain-size evolution and sociality in Carnivora. Proceedings of the National Academy of Sciences of the United States of America 106, 9345-9349.

Fleagle, J. G. (1978). Size distributions of living and fossil primate faunas. Paleobiology 4, 67-76.

Fleagle, J. G. (1985). Size and adaptation in primates. In Size and Scaling in Primate Biology (ed. W. L. Jungers), pp. 1-19. Plenum Press, New York.

Foth, C., Tischlinger, H. \& Rauhut, O. W. M. (2014). New specimen of Archaeopteryx provides insights into the evolution of pennaceous feathers. Nature 511, 79-82.

Friscia, A. R., Van Valkenburgh, B. \& Biknevicius, A. R. (2007). An ecomorphological analysis of extant small carnivorans. Journal of Zoology 272, $82-100$.

Gill, P. G., Purnell, M. A., Crumpton, N., Brown, K. R., Gostling, N. J., Stampanoni, M. \& Rayfield, E. J. (2014). Dietary specializations and diversity in feeding ecology of the earliest stem mammals. Nature 512, 303-305.

Gorniak, G. C. \& Gans, C. (1980). Quantitative assay of electromyograms during mastication in domestic cats (Felis catus). Journal of Morphology 163, 253-281.

GotThaRd, K. \& Nylin, S. (1995). Adaptive plasticity and plasticity as an adaptation: a selective review of plasticity in animal morphology and life history. Oikos 74, 3-17.

Gould, G. C. \& MacFadden, B. J. (2004). Gigantism, dwarfism, and Cope's rule: "nothing in evolution makes sense without a phylogeny". Bulletin of the American Museum of Natural History 285, 219-237.

Gupta, A. P. \& Lewontin, R. C. (1982). A study of reaction norms in natural populations of Drosophila pseudoobscura. Evolution 36, 934-948.

Hamrick, M. W., Skedros, J. G., Pennington, C. \& McNeil, P. L. (2006). Increased osteogenic response to exercise in metaphyseal versus diaphyseal cortical bone. Journal of Musculoskeletal and Neuronal Interactions 6, 258-263.

He, T. \& Kiliaridis, S. (2003). Effects of masticatory muscle function on craniofacial morphology on growing ferrets (Mustela putorius furo). European Journal of Oral Science 11, 510-517.

Heinrich, R. E., Ruff, C. B. \& Weishampel, D. B. (1993). Femoral ontogeny and locomotor biomechanics of Dryosaurus lettowvorbecki (Dinosauria, Iguanodontia). Zoological Journal of the Linnean Society 108, 179-196.

Herring, S. W. (1985). The ontogeny of mammalian mastication. American Zoologist 25, 339-349.

Herring, S. W. \& Scapino, R. P. (1973). Physiology of feeding in miniature pigs. Journal of Morphology 141, 427-460.

van Heteren, A. H., MacLarnon, A., Soligo, C. \& Rae, T. C. (2014). Functional morphology of the cave bear (Ursus spelaeus) cranium: a three-dimensional geometric morphometric analysis. Quaternary International 339/340, 209-216.

Hinton, R. J. \& McNamara, J. A. (1984). Effect of age on the adaptive response of the adult temporomandibular joint: a study of induced protrusion in Macaca mulatta. Angle Orthodontist 54, 154-162.

Hirano, T., Burr, D. B., Cain, R. L. \& Hock, J. M. (2000). Changes in geometry and cortical porosity in adult, ovary-intact rabbits after 5 months treatment with LY333334 (hPTH 1-34). Calcified Tissue International 66, 456-460.
Hirschfeld, Z., Michaeli, Y. \& Weinreb, M. M. (1977). Symphysis menti of the rabbit: anatomy, histology, and postnatal development. Journal of Dental Research 56, 850-857.

Hogg, R., Ravosa, M. J., Ryan, T. M. \& Vinyard, C. J. (2011). The functional morphology of the anterior masticatory apparatus in tree-gouging marmosets (Cebidae, Platyrrhini). Journal of Morphology 272, 833-849.

Holliday, C. M., Ridgely, R. C., Sedlmayr, J. C. \& Witmer, L. M. (2010). Cartilaginous epiphyses in extant archosaurs and their implications for reconstructing limb function in dinosaurs. PLoS ONE 5, e13120.

Holmes, M. A. \& Ruff, C. B. (2011). Dietary effects on development of the human mandibular corpus. American Journal of Physical Anthropology 145, $615-628$

Hoverman, J. T. \& Relyea, R. A. (2007). How flexible is phenotypic plasticity? Developmental windows for trait induction and reversal. Ecology 88, 693-705.

Hsieh, Y. F., Robling, A. G., Ambrosius, W. T., Burr, D. B. \& Turner, C. H. (2001). Mechanical loading of diaphyseal bone in vivo: the strain threshold for an osteogenic response varies with location. Journal of Bone and Mineral Research 16, 2291-2297.

Hylander, W. L. (1979a). Mandibular function in Galago crassicaudatus and Macaca fascicularis: an in vivo approach to stress analysis of the mandible. Journal of Morphology 159, 253-296.

Hylander, W. L. (1979b). The functional significance of primate mandibular form. Journal of Morphology 160, 223-240.

Hylander, W. L. \& Johnson, K. R. (1997). In vivo bone strain patterns in the zygomatic arch of macaques and the significance of these patterns for functional interpretations of craniofacial form. American Journal of Physical Anthropology 102, 203-232.

Hylander, W. L., Johnson, K. R. \& Crompton, A. W. (1992). Muscle force recruitment and biomechanical modeling: an analysis of masseter muscle function during mastication in Macaca fascicularis. American Journal of Physical Anthropology 88, 365-387.

Hylander, W. L., Pico, P. G. \& Johnson, K. R. (1991). Masticatory-stress hypotheses and the supraorbital region of primates. American Journal of Physical Anthropology 86, 1-36.

Hylander, W. L., Ravosa, M. J., Ross, C. F. \& Johnson, K. R. (1998). Mandibular corpus strain in primates: further evidence for a functional link between symphyseal fusion and jaw-adductor muscle force. American Journal of Physical Anthropology 107, 257-271.

Hylander, W. L., Ravosa, M. J., Ross, C. F., Wall, C. E. \& Johnson, K. R. (2000). Symphyseal fusion and jaw-adductor muscle force: an EMG study. American Journal of Physical Anthropology 112, 469-492.

Iinuma, M., Yoshida, S. \& Funakoshi, M. (1991). Development of masticatory muscles and oral behavior from suckling to chewing in dogs. Comparative Biochemistry and Physiology 100A, 789-794.

JANIS, C. M. (1995). Correlations between craniodental morphology and feeding behavior in ungulates: reciprocal illumination between living and fossil taxa. In Functional Morphology in Vertebrate Paleontology (ed. J. J. Thomason), pp. 76-98. Cambridge University Press, Cambridge.

Jašarević, E., Ning, J., Daniel, A. N., Menegaz, R. A., Johnson, J. J., Stack, M. S. \& RavosA, M. J. (2010). Masticatory loading, function and plasticity: a microanatomical analysis of mammalian circumorbital soft-tissue structures. Anatomical Record 293A, 642-650.

JERISON, H. J. (1979). Brain, body and encephalization in early primates. Journal of Human Evolution 8, 615-635.

Jungers, W. L. (1990). Problems and methods in reconstructing body size in fossil primates. In Body Size in Mammalian Paleobiology (eds J. Damuth and B. J. MacFadden), pp. 103-118. Cambridge University Press, Cambridge.

Kay, R. F. \& Cartmill, M. (1977). Cranial morphology and adaptations of Palaechthon nacimienti and other Paromomyidae (Plesiadapoidea, ?Primates), with a description of a new genus and species. Journal of Human Evolution $\mathbf{6}$, 19-35.

KосH, P. L. (1986). Clinal geographic variation in mammals: implications for the study of chronoclines. Paleobiology 12, 269-281.

Kohn, D. H., Sahar, N. D., Wallace, J. M., Golcuk, K. \& Morris, M. D. (2009). Exercise alters mineral and matrix composition in the absence of adding new bone. Cells, Tissues, Organs 189, 33-37.

Langenbach, G. E. J. \& van Eijden, T. M. G. J. (2001). Mammalian feeding motor patterns. American Zoologist 41, 1338-1351.

Langenbach, G. E. J., Weijs, W. A., Brugman, P. \& van Eijden, T. M. G. J. (2001). A longitudinal electromyographic study of the postnatal maturation of mastication in the rabbit. Archives of Oral Biology 46, 11-20.

Langenbach, G. E., Weijs, W. A. \& Koolstra, J. H. (1991). Biomechanical changes in the rabbit masticatory system during postnatal development. Anatomical Record 230, 406-416.

LAUDER, G. V. (1995). On the inference of function from structure. In Functional Morphology in Vertebrate Paleontology (ed.J.J. Thomason), pp. 1-18. Cambridge University Press, Cambridge. 
Lieberman, D. E., Krovitz, G. E., Yates, F. W., Devlin, M. \& St Claire, M. (2004). Effects of food processing on masticatory strain and craniofacial growth in a retrognathic face. Journal of Human Evolution 46, 655-677.

Maiorana, V. C. (1990). Evolutionary strategies and body size in a guild of mammals. In Body Size in Mammalian Paleobiology (eds J. DAMUtH and B. J. MacFadden), pp. 69-102. Cambridge University Press, Cambridge.

Marshall, A. J. \& Wrangham, R. W. (2007). Evolutionary consequences of fallback foods. International Journal of Primatology 28, 1219-1235.

Martin, R. D. (1990). Primate Origins and Evolution. Princeton University Press, Princeton.

MENEGAZ, R. A. (2013). Ecomorphological implications of primate dietary variability: an experimental model. PhD Thesis: University of Missouri, Columbia.

Menegaz, R. A., Sublett, S. V., Figueroa, S. D., Hoffman, T. J. \& Ravosa, M. J. (2009). Phenotypic plasticity and function of the hard palate in growing rabbits. Anatomical Record 292A, 277-284.

Menegaz, R. A., Sublett, S. V., Figueroa, S. D., Hoffman, T. J., Ravosa, M. J. \& Aldridge, K. (2010). Evidence for the influence of diet on cranial form and robusticity. Anatomical Record 293A, 630-641.

Meyer, A. (1987). Phenotypic plasticity and heterochrony in Cichlasoma managuense (Pisces, Cichlidae) and their implications for speciation in cichlid fishes. Evolution 41, 1357-1369.

Pearson, O. M. \& Lieberman, D. E. (2004). The aging of Wolff's "law": ontogeny and responses to mechanical loading in cortical bone. Yearbook of Physical Anthropology 39, 63-99.

Pigliucci, M. (2001). Phenotypic Plasticity: Beyond Nature and Nurture. Johns Hopkins University Press, Baltimore.

Pigliucci, M. (2005). Evolution of phenotypic plasticity: where are we going now? Trends in Ecology and Evolution 20, 481-486.

RADiNSKy, L. B. (1977). Early primate brains: facts and fiction. Journal of Human Evolution 6, 79-86.

RAdinSKy, L. B. (1982). Some cautionary notes on making inferences about relative brain size. In Primate Brain Evolution: Methods and Concepts (eds E. Armstrong and D. Falk), pp. 29-37. Plenum Press, New York.

RAdinsky, L. B. (1985). Approaches in evolutionary morphology: a search for patterns. Annual Review of Ecology and Systematics 16, 1-14.

Raia, P., Carotenuto, F., Passaro, F., Fulgione, D. \& Fortelius, M. (2012). Ecological specialization in fossil mammals explains Cope's Rule. American Naturalist 179, 328-337.

RaiA, P. \& Meiri, S. (2006). The island rule in large mammals: paleontology meets ecology. Evolution 60, 1731-1742.

RAvosA, M. J. (1991). Structural allometry of the prosimian mandibular corpus and symphysis. Journal of Human Evolution 20, 3-20.

Ravosa, M. J. (1996a). Jaw morphology and function in living and fossil Old World monkeys. International Journal of Primatology 17, 909-932.

Ravosa, M. J. (1996b). Mandibular form and function in North American and European Adapidae and Omomyidae. Journal of Morphology 229, $171-190$.

Ravosa, M. J. (1999). Anthropoid origins and the modern symphysis. Folia Primatologica 70, 65-78.

Ravosa, M. J. \& Hogue, A. S. (2004). Function and fusion of the mandibular symphysis in mammals: a comparative and experimental perspective. In Anthropoid Origins: New Visions (eds C. F. Ross and R. F. KAY), pp. 413-462. Kluwer/Plenum Publishers, New York.

Ravosa, M. J., Kunwar, R., Stock, S. R. \& Stack, M. S. (2007a). Pushing the limit: masticatory stress and adaptive plasticity in mammalian craniomandibular joints. Journal of Experimental Biology 210, 628-641.

Ravosa, M. J., Stock, S. R., Simons, E. L. \& Kunwar, R. (2007b). MicroCT analysis of symphyseal ontogeny in Archaeolemur. International Journal of Primatology 28, 1385-1396.

Ravosa, M. J., López, E. K., Menegaz, R. A., Stock, S. R., Stack, M. S. \& Hamrick, M. W. (2008a). Adaptive plasticity in the mammalian masticatory complex: you are what, and how, you eat. In Primate Craniofacial Biology and Function (eds C. J. Vinyard, M. J. Ravosa and C. E. WalL), pp. 293-328. Springer Academic Publishers, New York.

Ravosa, M. J., López, E. K., Menegaz, R. A., Stock, S. R., Stack, M. S. \& HAMrick, M. W. (2008b). Using "Mighty Mouse" to understand masticatory plasticity: myostatin-deficient mice and musculoskeletal function. Integrative and Comparative Biology 48, 345-359.

Ravosa, M. J., Ning, J., Costley, D. B., Daniel, A. N., Stock, S. R. \& Stack, M. S. (2010a). Masticatory biomechanics and masseter fiber-type plasticity. Journal of Musculoskeletal and Neuronal Interactions 10, 46-55.

Ravosa, M. J., Ross, C. F., Williams, S. H. \& Costley, D. B. (2010b). Allometry of masticatory loading parameters in mammals. Anatomical Record 293A, $557-571$.

Ravosa, M. J., Noble, V. E., Hylander, W. L., Johnson, K. R. \& Kowalski, E. M. (2000). Masticatory stress, orbital orientation and the evolution of the primate postorbital bar. Journal of Human Evolution 38, 667-693.
Richmond, B., Wright, B., Grosse, I., Dechow, P., Ross, C., Spencer, M. \& Strait, D. (2005). Finite element analysis in functional morphology. Anatomical Record 283A, 259-274.

RosE, K. D. (1990). Postcranial skeletal remains and adaptations in early Eocene mammals from the Willwood Formation, Bighorn Basin, Wyoming. GSA Special Papers 243, 107-134.

Ross, C. F. \& Metzger, K. A. (2004). Bone strain gradients and optimization in vertebrate skulls. Annals of Anatomy 186, 387-396.

Rотн, V. L. (1992). Inferences from allometry and fossils: dwarfing of elephants on islands. In Oxford Surveys in Evolutionary Biology (eds D. Futuyma and J. Antonovics), pp. 259-288. Oxford University Press, Oxford.

Rowe, T. B., MacrinI, T. E. \& Luo, Z.-X. (2011). Fossil evidence on origin of the mammalian brain. Science 332, 955-957.

Rubin, C. T., Bain, S. D. \& McLeod, K. J. (1992). Suppression of the osteogenic response in the aging skeleton. Calcified Tissue International 50, 306-313.

SCAPINO, R. P. (1981). Morphological investigation into functions of the jaw symphysis in carnivorans. Journal of Morphology 167, 339-375.

Schultz, S. \& Dunbar, R. (2010). Encephalization is not a universal macroevolutionary phenomenon in mammals but is associated with sociality. Proceedings of the National Academy of Sciences of the United States of America 107, 21582-21586.

Schwartz, G. T., Rasmussen, D. T. \& SMith, R. J. (1995). Body-size diversity and community structure of fossil hyracoids. Journal of Mammalogy 76, 1088-1099.

Schweitzer, M. H., Wittmeyer, J. L., Horner, J. R. \& Toporski, J. B. (2005). Soft tissue vessels and cellular preservation in Tyrannosaurus rex. Science 307, $1952-1955$.

Scott, J. E., Hogue, A. S. \& Ravosa, M. J. (2012a). The adaptive significance of mandibular symphyseal fusion in mammals. Journal of Evolutionary Biology 25, 661-673.

Scott, J. E., Lack, J. B. \& Ravosa, M. J. (2012b). On the irreversibility of mandibular symphyseal fusion. Evolution 66, 2940-2952.

Scott, J. E., McAbee, K. R., Eastman, M. M. \& Ravosa, M. J. (2014a). Experimental perspective on fallback foods and dietary adaptations in early hominins. Biology Letters 10, 20130789 (doi: 10.1098/rsbl.2013.0789).

Scott, J. E., McAbee, K. R., Eastman, M. M. \& Ravosa, M. J. (2014b). Teaching an old jaw new tricks: diet-induced plasticity in a model organism from weaning to adulthood. Journal of Experimental Biology 217, 4099-4107.

Secord, R., Bloch, J. I., Chester, S. G. B., Boyer, D. M., Wood, A. R., Wing, S. L., Kraus, M. J., McInerney, F. A. \& Krigbaum, J. (2012). Evolution of the earliest horses driven by climate change in the Paleocene-Eocene Thermal Maximum. Science 335, 959-962.

Silcox, M. T., Dalmyn, C. K. \& Bloch, J. I. (2009). Virtual endocast of Ignacius graybullianus (Paromomyidae, Primates) and brain evolution in early primates. Proceedings of the National Academy of Sciences of the United States of America 106, 10987-10992.

Skinner, M. M., Stephens, N. B., Tsegai, Z. J., Foote, A. C., Nguyen, N. H., Gross, T., Pahr, D. H., Hublin, J.J. \& Kivell, T. L. (2015). Human-like hand use in Australopithecus africanus. Science 347, 395-399.

SмiтH, R. J. (2002). Estimation of body mass in paleontology. Journal of Human Evolution 43, 271-287.

Smith, F. A., Boyer, A. G., Brown, J. H., Costa, D. P., Dayan, T., Ernest, S. K. M., Evans, A. R., Fortelius, M., Gittleman, J. L., Hamilton, M. J., Harding, L. E., Lintulaakso, K., Lyons, S. K., McCain, C., OKie, J. G., Sahininen, J. J., Sibly, R. M., Stephens, P. R., Theodor, J. \& Uhen, M. D. (2010). The evolution of maximum body size of terrestrial mammals. Science 330, $1216-1219$.

Sorensen, M. F., Rogers, J. P. \& Baskett, T. S. (1968). Reproduction and development in confined swamp rabbits. Journal of Wildlife Management 32 , $520-531$.

Spencer, M. A. \& Demes, B. (1993). Biomechanical analysis of masticatory system configuration in Neandertals and Inuits. American Journal of Physical Anthropology 91, 1-20.

Standen, E. M., Du, T. Y. \& Larsson, H. C. E. (2014). Developmental plasticity and the origin of tetrapods. Nature $513,54-58$.

StEarns, S. C. (1989). The evolutionary significance of phenotypic plasticity. BioScience 39, 436-445.

Steiper, M. E. \& Seiffert, E. R. (2012). Evidence for a convergent slowdown in primate molecular rates and its implications for the timing of early primate evolution. Proceedings of the National Academy of Sciences of the United States of America 109, 6006-6011.

Strait, D. S., Weber, G. W., Neubauer, S., Chalk, J., Richmond, B. G., Lucas, P. W., Spencer, M. A., Schrein, C., Dechow, P. C., Ross, C. F., Grosse, I. R., Wright, B. W., Constantino, P., Wood, B. A., Lawn, B., Hylander, W. L., Wang, Q., Byron, C., Slice, D. E. \& Smith, A. L. (2009). The feeding biomechanics and dietary ecology of Australopithecus africanus. Proceedings of the National Academy of Sciences of the United States of America 106, 2124-2129. 
Taylor, A. B., Jones, K. E., Kunwar, R. \& Ravosa, M. J. (2006). Dietary consistency and plasticity of masseter fiber architecture in postweaning rabbits. Anatomical Record 288A, 1105-1111.

Taylor, A. B., Vogel, E. R. \& Dominy, N. J. (2008). Food material properties and mandibular load resistance abilities in large-bodied hominoids. Journal of Human Evolution 55, 604-616.

Terborgh, J. (1983). Five New World Primates. Princeton University Press, Princeton.

Tutin, C. E. G. \& Fernandez, M. (1993). Composition of the diet of chimpanzees and comparisons with that of sympatric lowland gorillas in the Lopé Reserve, Gabon. International Journal of Primatology 30, 195-211.

UnGaR, P. S. \& KAY, R. F. (1995). The dietary adaptations of European Miocene catarrhines. Proceedings of the National Academy of Sciences of the United States of America 92, 5479-5481

VAn VAlkenburgh, B. (1982). Skeletal indicators of locomotor behavior in living and extinct carnivores. Journal of Vertebrate Paleontology 7, 162-182.

Villmoare, B. A. \& Kimbel, W. H. (2011). CT-based study of internal structure of the anterior pillar in extinct hominins and its implications for the phylogeny of robust Australopithecus. Proceedings of the National Academy of Sciences of the United States of America 108, 16200-16205.

Vinyard, C. J., Taylor, A. B., Teaford, M. F., Glander, K. E., Ravosa, M. J., Rossie, J. B., Ryan, T. M. \& Williams, S. H. (2011). Are we looking for loads in all the right places? New research directions for studying the masticatory apparatus of New World monkeys. Anatomical Record 294, 2140-2157.

Vinyard, C. J., Yamashita, N. \& TAN, C. (2008). Linking laboratory and field approaches in studying the evolutionary physiology of biting in bamboo lemurs. International Journal of Primatology 29, 1421-1439.

Wallace, J. M., Golcuk, K., Morris, M. D. \& Kohn, D. H. (2010). Inbred strain-specific effects of exercise in wild type and biglycan deficient mice. Annals of Biomedical Engineering 38, 1607-1617.

Wallace, J. M., Ron, M. S. \& Kohn, D. H. (2009). Short-term exercise in mice increases tibial post-yield mechanical properties while two weeks of latency following exercise increases tissue-level strength. Calcified Tissue International 84, 297-304.

Weijs, W. A., Brugman, P. \& Grimbergen, C. A. (1989). Jaw movements and muscle activity during mastication in growing rabbits. Anatomical Record 224, 407-416.

Weijs, W. A., Brugman, P. \& Klok, E. M. (1987). The growth of the skull and jaw muscles and its functional consequences in the New Zealand rabbit (Oryctolagus cuniculus). Journal of Morphology 194, 143-161.
Weijs, W. A. \& Dantuma, R. (1981). Functional anatomy of the masticatory apparatus in the rabbit (Oryctolagus cuniculus L.). Netherlands Journal of Zoology 31, 99-147.

WeIJs, W. A. \& DE JONGH, H. J. (1977). Strain in mandibular alveolar bone during mastication in the rabbit. Archives of Oral Biology 22, 667-675.

West-Eberhard, M. J. (2003). Developmental Plasticity and Evolution. Oxford University Press, Oxford.

West-Eberhard, M.J. (2005). Developmental plasticity and the origin of species differences. Proceedings of the National Academy of Sciences of the United States of America 102, 6543-6549.

Westneat, M. W. \& Hall, W. G. (1992). Ontogeny of feeding motor patterns in infant rats: an electromyographic analysis of suckling and chewing. Behavioral Neurology 106, 539-554.

White, T. D., Asfaw, B., Beyene, Y., Haile-Selassie, Y., Lovejoy, C. O., Suwa, G. \& WoldeGabriel, G. (2009). Ardipithecus ramidus and the paleobiology of early hominids. Science $\mathbf{3 2 6}, 75-86$.

Williams, S. H., Wright, B. W., Truong, V. D., Daubert, C. R. \& Vinyard, C. J. (2005). Mechanical properties of foods used in experimental studies of primate masticatory function. American Journal of Primatology 67, 329-346.

WitMer, L. M. (1995). The extant phylogenetic bracket and the importance of reconstructing soft tissues in fossils. In Functional Morphology in Vertebrate Paleontology (ed. J. J. Thomason), pp. 19-33. Cambridge University Press, Cambridge.

WRIGHT, B. W. (2005). Craniodental biomechanics and dietary toughness in the genus Cebus. Journal of Human Evolution 48, 473-492.

Yamada, K. \& Kimmel, D. B. (1991). The effect of dietary consistency on bone mass and turnover in the growing rat mandible. Archives of Oral Biology $\mathbf{3 6}$ $129-138$.

Yamashita, N., Vinyard, C. J. \& Tan, C. L. (2009). Food mechanical food properties in three sympatric species of Hapalemur in Ranomafana National Park, Madagascar. American Journal of Physical Anthropology 139, 368-381.

YARdin, M. (1974). Sur l'ontogénèse de la mastication chez le lapin (Oryctolagus cuniculus). Mammalia 38, 737-747.

Young, M. T., Rayfield, E. J., Holliday, C. M., Witmer, L. M., Button, D. J., Upchurch, P. \& Barrett, P. M. (2012). Cranial biomechanics of Diplodocus (Dinosauria, Sauropoda): testing hypotheses of feeding behaviour in an extinct megaherbivore. Naturwissenschaften 99, 637-643.

(Received 26 August 2014; revised 8 May 2015; accepted 15 May 2015) 